\title{
Electronic Nature of the Aromatic Adamantanediyl Ions and its Analogues
}

\author{
Caio L. Firme, O. A. C. Antunes and Pierre M. Esteves*
}

Instituto de Química, Universidade Federal do Rio de Janeiro, Av. Athos da Silveira Ramos, 149, CT Bloco A, $6^{\circ}$ andar, Cidade Universitária, Ilha do Fundão, 21941-909 Rio de Janeiro-RJ, Brazil

A estabilidade relativa do dicátion 1,3-desidro-5,7-adamantanediila é atribuída a sua aromaticidade tridimensional. Contudo, sua natureza eletrônica não é bem conhecida. A fim de entendê-la melhor, os di- e monocátions do adamantanodiil e alguns de seus análogos foram estudados utilizando a teoria de átomos e moléculas (AIM). Eles foram comparados com análogos de adamantano não-aromáticos. Os resultados de AIM indicam que a densidade eletrônica no centro da estrutura em gaiola e a média de todos os índices de deslocalização, envolvendo seus átomos cabeças-de-ponte são maiores em compostos aromáticos do que em não-aromáticos. A degenerescência energética dos átomos cabeça-de-ponte, a uniformidade e magnitude da carga compartilhada entre estes, distingue os dicátions 1,3-adamantila e 1,3-desidro-5,7-adamantanediila. Contudo, ambos são aromáticos, assim como o 1,3-desidro-5,7-diboroadamantano. $\mathrm{O}$ cátion 1,3-desidro-7-adamantila tem uma homoaromaticidade planar característica.

The relative stability of the 1,3-dehydro-5,7-adamantanediyl dication is ascribed to its tridimensional aromaticity. However, its electronic nature is not well known. In order to improve its understanding, dicationic and monocationic adamantanedyil species and some key analogues were studied by atoms in molecules (AIM) theory. They were compared to non-aromatic adamantane analogues. AIM results indicate that the density in center of the cage structure and the average of all delocalization indexes involving its bridged atoms are higher in aromatic than in non-aromatic compounds. Degeneracy in energy of the bridged atoms, uniformity and magnitude of their shared charge distinguish the dications 1,3-adamantyl and the 1,3-dehydro-5,7-adamantanediyl. However, both are aromatic as well as the 1,3-dehydro-5,7-diboroadamantane. The 1,3-dehydro-7-adamantyl cation has a characteristic planar homoaromaticity.

Keywords: adamantyl dication, adamantyl cation, degeneracy, delocalization index, ring density, aromaticity, tridimensional aromaticity, 1,3-dehydro-5,7-adamantanediyl dication

\section{Introduction}

Some cationic adamantanediyl species are relatively stable intermediates, e.g., Schleyer's 1,3-dehydro-5,7adamantanediyl dication (Scheme 1). The adamantanediyl monocation is a stable species and can be synthesized from the 1-adamantanol and fluorosulfonic acid-antimony pentafluoride. ${ }^{1}$ The adamantanediyl dication has not been observed as persistent long-lived species so far. ${ }^{2}$ Ionization of 1,3-difluoroadamantane in superacids afforded only the monocation complex ${ }^{3} \mathrm{C}_{10} \mathrm{H}_{14} \mathrm{~F}_{-}-\mathrm{SbF}_{5}$ (Scheme 1). Attempts of obtaining other adamantane-1,3-diyl dications were not

*e-mail: pesteves@iq.ufrj.br successful. ${ }^{4}$ However, the 1,3-dehydro-5,7-adamantanediyl dication (or 1,3,5,7-bisdehydroadamantane dication) is a stable species. ${ }^{5}$ It exhibits shielded bridgehead carbons at $\delta$ $6.6 \mathrm{ppm}$ with methylene carbon resonances appearing at $\delta$ $35.6 \mathrm{ppm}$ which is characteristic of hypercoordinate carbocations. ${ }^{5}$ Despite that 1,3,5,7-tetrasilaadamantane (Scheme 1) is easily obtained ${ }^{6}$ from the $1,3,5$-hexamethyl-1,3,5trisilacyclohexane and $\mathrm{AlBr}_{3}$, the 1,3-dehydro-5,7-tetrasilaadamantanediyl dication is not observed experimentally. However, it has a spherical homoaromaticity ${ }^{7}$ which is another name for the tridimensional aromaticity.

A series of isoelectronic analogues of the adamantane and its dehydroadamantanes containing boron, nitrogen, and phosphorus atoms at bridgehead were studied and the three- 

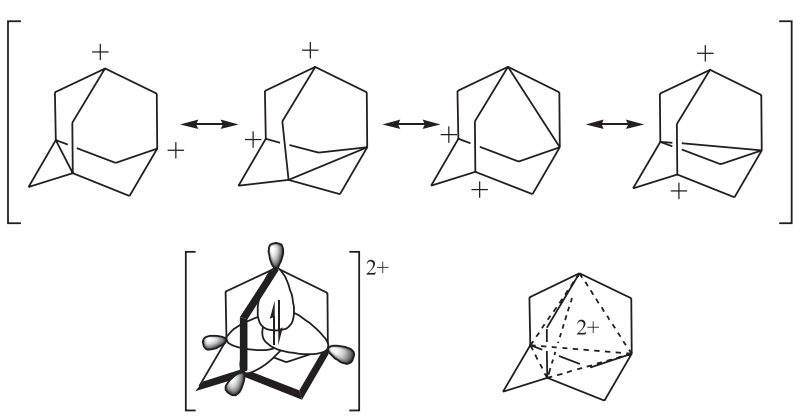

1,3-dehydro-5,7-adamantanediyl dication

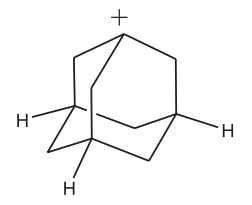

Adamanty 1 cation

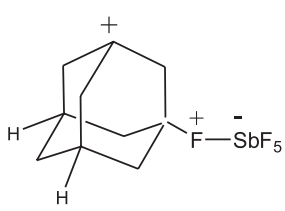

Fluoroadamantyl- $\mathrm{SbF}_{5}$ cation
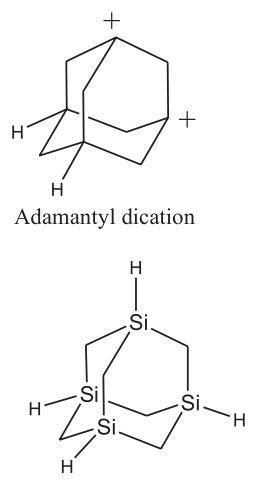

1,3,5,7-tetrasilaadamantane
Scheme 1.

dimensional aromaticity is found to be general for $4 c-2 e$ electron systems. ${ }^{8}$ The calculations of the isoeletronic boron and diboron analogues of the 1,8-dehydrohomoadamantanediyl3,6-dication, $\mathrm{BC}_{9} \mathrm{H}_{12}{ }^{+}$and $\mathrm{B}_{2} \mathrm{C}_{8} \mathrm{H}_{12}$, respectively, indicate that both have three-dimensional aromaticity. ${ }^{9}$

Despite that 1,3-dehydroadamantane undergoes addition reaction easily, ${ }^{10}$ it is stable at low temperature and inert conditions. Hitherto, the 1,3-dehydro-5-adamantyl cation is not a long-lived stable ion but it is an intermediate in solvolysis of the 5-bromo-1,3-dehydroadamantane. ${ }^{11}$ The density functional theory (DFT) study showed that the 1,3-dehydro-5-adamantyl cation has $20.0 \mathrm{kcal} \mathrm{mol}^{-1}$ stabilization due to trishomoaromatic interaction. ${ }^{9}$ The 1,3-dehydro-5-boroadamantyl analogue has the same type of stabilization. ${ }^{9}$

The three-dimensional aromaticity of 1,3-dehydro-5,7adamantanediyl dication is explained in terms of overlap among four p-orbitals in a tetrahedral fashion (Scheme 1) and its ${ }^{13} \mathrm{C}$ NMR spectrum has a single absorption $\left(\delta^{13} \mathrm{C}\right.$ $6.6 \mathrm{ppm}$ ) assigned for bridgehead carbons. ${ }^{12}$ In order to understand the electronic nature of these systems we have performed AIM calculations of the 1,3-dehydro-5-7adamantanediyl dication and its analogues.

\section{Computational Methods}

Geometry optimization, vibrational analysis and the generation of the electronic density were obtained with GAUSSIAN 03 package. ${ }^{13}$ The geometries were optimized in DFT level employing Becke three-parameter interchange functional ${ }^{14}$ (B3) in conjunction with Lee-Yang-Parr ${ }^{15}$ correlation functional (LYP) and the split valence basis set ${ }^{16}$ 6-311++G**. Dehalogenation calculations were performed at the same level. All geometries were characterized as stationary points after vibrational analysis.

The AIM 2000 software ${ }^{17}$ was used for charge density calculations from the electronic densities ( $\rho$ ) obtained at B3LYP/6$311++\mathrm{G}^{* *}$ level. NICS ${ }^{18}$ (nucleus independent chemical shift) calculations were performed at GIAO/B3LYP/6-311++G** level at the geometric center of the cage.

\section{Rationale}

Within the molecular orbital theory (MO) the aromatic character of benzene is explained through delocalized orbitals. Nevertheless by using spin coupled from valence bond theory (SC), Gerratt and co-workers ${ }^{19}$ established that all six $\omega$ electrons of benzene are localized and distorted symmetrically towards neighboring carbon atoms on each side and possess same energy and shape. Furthermore, from a more rigorous quantum mechanical standpoint, ${ }^{20}$ benzene has no resonance ${ }^{21}$ since there is not intersection of degenerate point group states. It means that benzene ( $\mathrm{D}_{6 \mathrm{~h}}$ symmetry) cannot be related to Kekulé $\left(\mathrm{D}_{3 \mathrm{~h}}\right.$ symmetry) or Dewar $\left(\mathrm{D}_{2 \mathrm{~h}}\right)$ structures. In this case, benzene stability is ascribed to maximum overlap among six degenerate single-electron states. ${ }^{22}$ Then, in modern valence bond theory (VB), the idea of aromaticity is based on the overlap and degeneracy of the single-electron states. ${ }^{22}$

The index used to study the aromaticity of adamantanediyl ions and its analogues in this work, $\mathrm{D}_{3} \mathrm{BIA}$, is inspired to the modern VB idea of aromaticity. The modern VB parameters of aromaticity can be associated with topological parameters. Then, it is possible to quantify aromaticity by AIM theory inspired on modern VB ideas of aromaticity. In the case of adamantanediyl ions and its analogues, the aromaticity from modern VB theory can be associated with the energy of atomic basins of the bridged atoms, the charge density in the cage critical point and the delocalization indexes involving the bridged atomic pairs of the cage (from AIM). The use of Kohn-Sham orbitals for the calculation of delocalization indices is a good approximation, although not strictly correct.

It is important to emphasize that the calculus of energy of an atomic basin is an one-electron integration over the whole atomic basin. Then, the AIM provides the energy value of the total energy of each atomic basin. Since degeneracy in Quantum Chemistry means same energy, the AIM can provide the information whether some atomic basins in a given molecular system are degenerate or not (see Electronic Supplementary Information for more details). 


\section{Results and Discussions}

The studied species are depicted in Scheme 2. The AIM theory ${ }^{23}$ is based on the analysis of the electronic density distribution, $\rho(r)$, obtained from a quantum mechanical wavefunction. Although DFT does not generate a wave function, it yields a density matrix similar to that from a post-HF method such as MP2. Much information can be obtained from AIM such as the bond, cage and ring critical points and their respective eigenvalues (see electronic supplementary information).

Table 1 contains the delocalization indexes and energy of bridged atoms ( $\mathrm{R}^{1}, \mathrm{R}^{3}, \mathrm{R}^{5}$ and $\left.\mathrm{R}^{7}\right)$ of the species $\mathbf{1}$ to $\mathbf{3 2}$, obtained from AIM theory. Their analysis allows the investigation of the electronic differences between aromatic and non-aromatic tridimensional systems. Table 1 also contains the point group symmetry of each studied species.

The delocalization index (DI) is a measure of number of electrons that are shared or exchanged between two atoms or basins. The integration of the Fermi hole density through a pair density matrix leads to the localization index (LI) and the delocalization index ${ }^{24}$ (DI). Although DFT does not yield a pair density matrix, the delocalization indexes from B3LYP are close to those from MP2 (see electronic supplementary information). It is important to emphasize that the delocalization index does not measure the delocalization of valence electrons over the whole molecular system.

In a previous work on benzene-like compounds it was shown the importance of some electronic parameters to determine their aromaticity. ${ }^{25}$ These parameters were degeneracy of the atoms in the ring, density inside the ring and uniformity of delocalization index between atoms of the ring. All of these parameters are also analyzed in this work.

The bridged atoms of the adamantane $\mathbf{1}$ and the 3-dehydro-5,7-adamantanediyl dication $\mathbf{1 6}$ are degenerate and the delocalization indexes (or amount of shared charge density) among them are uniform in both molecules (0.039 in $\mathbf{1}$ and 0.280 in 16). However, the delocalization indexes in $\mathbf{1 6}$ are seven-fold higher than those in 1. As a consequence, the species $\mathbf{1 6}$ has $1.70 \mathrm{e}$ among the bridged atoms while the species $\mathbf{1}$ has only $0.23 \mathrm{e}$.

The delocalization indexes among bridged atoms in adamantyl dication $\mathbf{1 0}$ are not uniform $(0.079,0.147$ and 0.143 ) and the energy of its bridged atoms is not degenerate (Table 1). The degeneracy of bridged atoms, uniformity and magnitude of their delocalization indexes are the electronic features that distinguish the species $\mathbf{1 0}$ and 16. They can be regarded as determinant factors for the relative stability of the 1,3-dehydro-5,7-adamantanediyl dication. One simi-

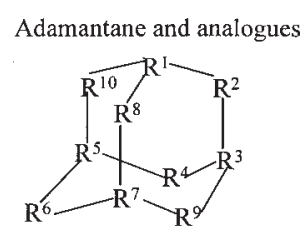

1. $R^{1}=R^{3}=R^{5}=R^{7}=C H$

2. $R^{1}=R^{3}=R^{5}=R^{7}=S i H$

3. $R^{1}=R^{3}=C H ; R^{5}=R^{7}=S i H$

4. $R^{1}=R^{3}=N ; R^{5}=R^{7}=C H$

5. $R^{1}=R^{3}=N ; R^{5}=R^{7}=S i H$

6. $\mathrm{R}^{1}=\mathrm{R}^{3}=\mathrm{B} ; \mathrm{R}^{5}=\mathrm{R}^{7}=\mathrm{CH}$

7. $R^{2}=R^{4}=R^{8}=R^{9}=R^{10}=0$

$R^{1}=R^{3}=R^{5}=R^{7}=C H ; R^{6}=C H_{2}$
$R^{2}=R^{4}=R^{8}=R^{9}=R^{10}=O$

$R^{1}=R^{3}=R^{5}=R^{7}=S i H ; R^{6}=C_{2}$

9. $\mathrm{R}^{2}=\mathrm{R}^{4}=\mathrm{R}^{8}=\mathrm{R}^{9}=\mathrm{R}^{10}=\mathrm{O}$

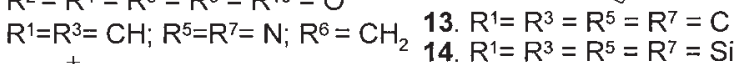

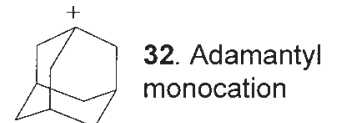

Diamantyl dication
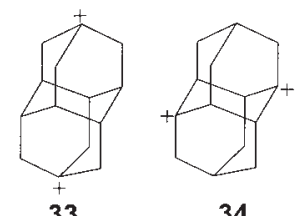

34
Adamantyl dication and analogues

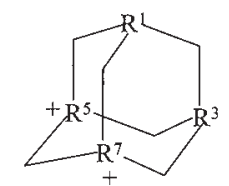

10. $R^{1}=R^{3}=C H ; R^{5}=R^{7}=C$

11. $\mathrm{R}^{1}=\mathrm{R}^{3}=\mathrm{SiH} ; \mathrm{R}^{5}=\mathrm{R}^{7}=\mathrm{Si}$

12. $R^{1}=R^{3}=C H ; R^{5}=R^{7}=S i$ Bisdehydroadamantane and analogues

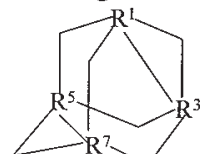

15. $R^{1}=R^{5}=N^{+} ; R^{3}=R^{7}=B^{-}$

1,3-Dehydro-5 adamantanedyil monocation and analogues

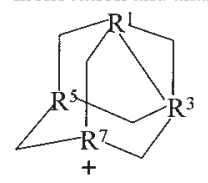

25. $R^{1}=R^{3}=R^{7}=C ; R^{5}=C H$ 26. $R^{1}=R^{3}=R^{7}=S i ; R^{5}=S i H$ 27. $R^{\mathfrak{l}}=\mathrm{R}^{3}=\mathrm{C} ; \mathrm{R}^{7}=\mathrm{Si} ; \mathrm{R}^{5}=\mathrm{SiH}$ 1,3-dehydro-5,7-

adamantanediyl dication

and analogues

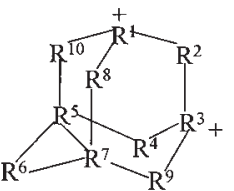

16. $R^{1}=R^{3}=R^{5}=R^{7}=C$

17. $R^{1}=R^{3}=R^{5}=R^{7}=S i$

18. $R^{1}=R^{3}=C ; R^{5}=R^{7}=S i$

19. $R^{1}=R^{3}=N H ; R^{5}=R^{7}=C$

20. $R^{1}=R^{3}=N H ; R^{5}=R^{7}=S i$

21. $R^{1}=N^{+} ; R^{3}=B^{*} ; R^{5}=R^{7}=C$

22. $R^{2}=R^{4}=R^{8}=R^{9}=R^{10}=0$

$R^{1}=R^{3}=R^{5}=R^{7}=C ; R^{6}=C H_{2}$
$R^{2}=R^{4}=R^{8}=R^{9}=R^{10}=O$

$\mathrm{R}^{1}=\mathrm{R}^{3}=\mathrm{R}^{5}=\mathrm{R}^{7}=\mathrm{Si} ; \mathrm{R}^{6}=\mathrm{CH}_{2}$

24. $R^{2}=R^{4}=R^{8}=R^{9}=R^{10}=0$

$\mathrm{R}^{1}=\mathrm{R}^{3}=\mathrm{NH} ; \mathrm{R}^{5}=\mathrm{R}^{7}=\mathrm{C} ; \mathrm{R}^{6}=\mathrm{CH}_{2}$

1,3-Dehydro-5,7-

adamantane and analogues

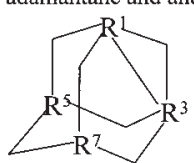

28. $\mathrm{R}^{1}=\mathrm{R}^{3}=\mathrm{C} ; \mathrm{R}^{5}=\mathrm{R}^{7}=\mathrm{CH}$

29. $R^{1}=R^{3}=C ; R^{5}=R^{7}=B$

30. $R^{1}=R^{5}=S i ; R^{3}=R^{7}=B$

31. $R^{1}=N^{+} ; R^{3}=B^{-} ; R^{5}=R^{7}=B$

Scheme 2. 
Table 1. Delocalization index among bridged atoms, energy of bridged atoms and point group symmetry of the species $\mathbf{1}$ to $\mathbf{3 2}$

\begin{tabular}{|c|c|c|c|c|c|c|c|c|c|c|c|}
\hline \multirow{2}{*}{ Entry } & \multicolumn{6}{|c|}{ Delocalization index } & \multicolumn{4}{|c|}{ Energy / au } & \multirow{2}{*}{$\begin{array}{c}\text { Point group } \\
\text { symmetry }\end{array}$} \\
\hline & $\mathrm{R}^{1}-\mathrm{R}^{3}$ & $\mathrm{R}^{1}-\mathrm{R}^{5}$ & $\mathrm{R}^{1}-\mathrm{R}^{7}$ & $\mathrm{R}^{3}-\mathrm{R}^{7}$ & $\mathrm{R}^{3}-\mathrm{R}^{5}$ & $\mathrm{R}^{5}-\mathrm{R}^{7}$ & $\mathrm{R}^{1}$ & $\mathrm{R}^{3}$ & $\mathrm{R}^{5}$ & $\mathrm{R}^{7}$ & \\
\hline 1 & 0.039 & 0.039 & 0.039 & 0.039 & 0.039 & 0.039 & -38.06 & -38.06 & -38.06 & -38.06 & $\mathrm{Td}$ \\
\hline 2 & 0.007 & 0.007 & 0.007 & 0.007 & 0.007 & 0.007 & -288.81 & -288.81 & -288.81 & -288.81 & $\mathrm{C}_{1}$ \\
\hline 3 & 0.038 & 0.016 & 0.016 & 0.016 & 0.016 & 0.008 & -37.91 & -37.91 & -289.04 & -289.04 & $\mathrm{Cs}$ \\
\hline 4 & 0.107 & 0.068 & 0.068 & 0.068 & 0.068 & 0.041 & -55.21 & -55.21 & -38.07 & -38.07 & $\mathrm{C}_{1}$ \\
\hline 5 & 0.119 & 0.034 & 0.034 & 0.034 & 0.034 & 0.009 & -55.06 & -55.07 & -289.04 & -289.04 & Cs \\
\hline 6 & 0.026 & 0.033 & 0.033 & 0.033 & 0.033 & 0.045 & -24.10 & -24.10 & -38.01 & -38.01 & $\mathrm{Cs}$ \\
\hline 7 & 0.022 & 0.023 & 0.023 & 0.023 & 0.023 & 0.045 & -37.18 & -37.18 & -37.50 & -37.50 & Cs \\
\hline 8 & 0.008 & 0.006 & 0.006 & 0.006 & 0.006 & 0.006 & -288.55 & -288.55 & -288.46 & -288.44 & Cs \\
\hline 9 & 0.049 & 0.045 & 0.045 & 0.045 & 0.045 & 0.091 & -37.54 & -37.55 & -54.37 & -54.37 & $\mathrm{C}_{1}$ \\
\hline 10 & 0.079 & 0.147 & 0.147 & 0.147 & 0.147 & 0.143 & -38.01 & -38.01 & -38.13 & -38.13 & Cs \\
\hline 11 & 0.023 & 0.023 & 0.024 & 0.023 & 0.023 & 0.011 & -288.89 & -288.82 & -288.90 & -288.82 & $\mathrm{C}_{1}$ \\
\hline 12 & 0.056 & 0.061 & 0.061 & 0.061 & 0.061 & 0.033 & -37.92 & -37.92 & -289.10 & -289.10 & $\mathrm{C}_{1}$ \\
\hline 13 & 0.825 & 0.081 & 0.082 & 0.082 & 0.082 & 0.829 & -38.12 & -38.12 & -38.12 & -38.12 & $\mathrm{C}_{1}$ \\
\hline 14 & 0.102 & 0.070 & 0.086 & 0.106 & 0.146 & 0.091 & -288.99 & -289.15 & -289.16 & -288.99 & $\mathrm{C}_{1}$ \\
\hline 15 & 0.073 & 0.144 & 0.073 & 0.031 & 0.069 & 0.069 & -55.14 & -24.11 & -55.15 & -24.11 & $\mathrm{C}_{1}$ \\
\hline 16 & 0.280 & 0.280 & 0.280 & 0.280 & 0.280 & 0.280 & -38.09 & -38.10 & -38.09 & -38.09 & $\mathrm{C}_{1}$ \\
\hline 17 & 0.097 & 0.096 & 0.096 & 0.097 & 0.097 & 0.096 & -288.97 & -288.97 & -288.97 & -288.97 & $\mathrm{C}_{1}$ \\
\hline 18 & 0.153 & 0.140 & 0.140 & 0.140 & 0.140 & 0.183 & -289.22 & -289.22 & -38.02 & -38.02 & $\mathrm{Cs}$ \\
\hline 19 & 0.065 & 0.085 & 0.085 & 0.085 & 0.085 & 0.836 & -38.13 & -38.13 & -55.21 & -55.21 & $\mathrm{Cs}$ \\
\hline 20 & 0.010 & 0.019 & 0.019 & 0.019 & 0.019 & 0.068 & -288.99 & -288.99 & -55.07 & -55.07 & $\mathrm{Cs}$ \\
\hline 21 & 0.147 & 0.254 & 0.253 & 0.107 & 0.107 & 0.184 & -55.20 & -24.12 & -38.10 & -38.10 & $\mathrm{C}_{1}$ \\
\hline 22 & 0.137 & 0.158 & 0.158 & 0.158 & 0.158 & 0.248 & -37.03 & -37.03 & -37.41 & -37.41 & $\mathrm{C}_{1}$ \\
\hline 23 & 0.151 & 0.119 & 0.118 & 0.118 & 0.119 & 0.057 & -288.55 & -288.55 & -288.66 & -288.66 & $\mathrm{C}_{1}$ \\
\hline 24 & 0.046 & 0.060 & 0.060 & 0.060 & 0.060 & 0.804 & -54.47 & -54.47 & -37.61 & -37.61 & $\mathrm{C}_{1}$ \\
\hline 25 & 0.410 & 0.071 & 0.410 & 0.410 & 0.071 & 0.071 & -38.12 & -38.12 & -38.04 & -38.12 & $\mathrm{C}_{1}$ \\
\hline 26 & 0.155 & 0.019 & 0.155 & 0.155 & 0.019 & 0.019 & -289.03 & -289.03 & -288.82 & -289.03 & $\mathrm{C}_{1}$ \\
\hline 27 & 0.217 & 0.034 & 0.217 & 0.217 & 0.034 & 0.028 & -38.03 & -38.03 & -289.03 & -289.33 & $\mathrm{C}_{1}$ \\
\hline 28 & 0.855 & 0.062 & 0.062 & 0.062 & 0.062 & 0.036 & -38.15 & -38.15 & -38.04 & -38.04 & $\mathrm{C}_{1}$ \\
\hline 29 & 0.319 & 0.113 & 0.113 & 0.113 & 0.113 & 0.041 & -38.12 & -38.12 & -24.12 & -24.12 & $\mathrm{C}_{1}$ \\
\hline 30 & 0.228 & 0.055 & 0.055 & 0.055 & 0.055 & 0.026 & -289.28 & -289.28 & -24.04 & -24.04 & $\mathrm{C}_{1}$ \\
\hline 31 & 0.103 & 0.103 & 0.103 & 0.029 & 0.029 & 0.029 & -55.19 & -24.11 & -24.11 & -24.11 & $\mathrm{C}_{1}$ \\
\hline 32 & 0.112 & 0.112 & 0.112 & 0.053 & 0.053 & 0.053 & -38.16 & -38.04 & -38.04 & -38.04 & Cs \\
\hline
\end{tabular}

larity between the species $\mathbf{1 0}$ and $\mathbf{1 6}$ is that their positive charge is distributed among the hydrogen atoms, as one can see in Figure 1.

The relative stability of the 1,3-dehydro-7-adamantyl cation $\mathbf{2 5}$ is experimentally known. ${ }^{3}$ It is suggested that the species 25 (Figure 1) has homoaromaticity among $\mathrm{R}^{1}, \mathrm{R}^{3}$, and $\mathrm{R}^{7}$ bridged atoms (see Table 2 ) since they are nearly degenerate. Besides, the delocalization indexes among these atoms have high magnitude and uniformity.

When bridgehead carbon atoms are substituted by silicon atoms, such as in $\mathbf{2 , 1 1 , 1 7}$ and $\mathbf{2 6}$, it is noteworthy that their respective delocalization indexes decrease significantly (Table 2). All other electronic features remain the same when comparing the silicon derivatives with their carbon analogues 1, 10, 16 and 25, respectively. Bridged silicon atoms in $\mathbf{1 7}$ are nearly degenerate and the delocalization indexes among them are nearly uniform. However, the magnitude of these delocalization indexes is almost three-fold smaller than that from 16. The same occurs with $\mathbf{2 6}$ in comparison to $\mathbf{2 5}$.

In $3, \mathbf{1 2}, 18$ and 27 , only two carbon bridged atoms are replaced by silicon ones. This change decreases 


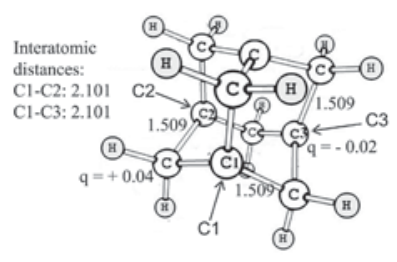

16

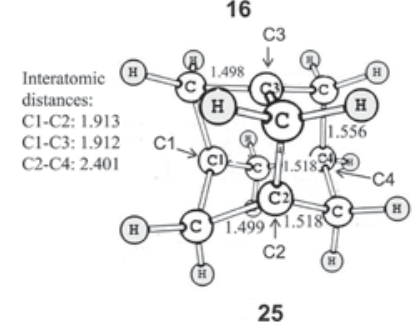

25
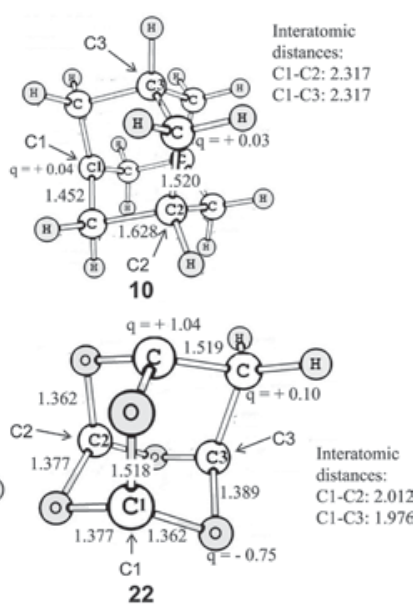

22
Figure 1. Bond lengths, interatomic distances $(\AA)$ and atomic charge (in atomic units) of 1,3-dehydro-5-7-adamantanediyl dication 16, 1,3adamantyl dication 10, 1,3-dehydro-7-adamantyl cation 25 and oxyspecies 22

degeneracy of their bridged atoms due to a decrease on the symmetry of their respective species. In $\mathbf{3}$ and $\mathbf{1 8}$ there is no uniformity of delocalization indexes involving the bridgehead atoms. The exception is the species 27 . As to the magnitude of delocalization indexes, 3, 12, 18 and 27 have higher values than those from their respective analogues 2, 11, 17 and 26.

From AIM electronic analysis, bisdehydro-1,3,5,7adamantane $\mathbf{1 3}$ and the 1,3-dehydro-5,7-adamantane $\mathbf{2 8}$ do not have tridimensional aromaticity since the delocalization indexes among their bridged atoms are not uniform. Moreover, they are smaller than those from 16 (except for the DI's between C-C bonds). The non-stability of bisdehydro$1,3,5,7$-adamantane ${ }^{8}$ is probably due to its anti-aromatic $4 n$-electron character. The bridged silicon analogue of $\mathbf{1 3}$, bisdehydro-1,3,5,7-tetrasilaadamantane 14, has no Si-Si bonds (Figure 2b). However, its delocalization indexes are not so much different than those from $\mathbf{1 8}$ which has only 2 electrons among bridged atoms.

In oxy-species 7, 8, 22 and 23 there is no degeneracy of bridged atoms and uniformity of delocalization indexes among them. By comparing oxy-species with bridged carbon atoms (7 and 22) with their analogues $\mathbf{1}$ and 16, one can see that the magnitude of the DI's decreases significantly in 7 and 22 due to the higher electronegativity of the oxygen atom. However, this does not happen with oxy-species with bridged silicon atoms ( 8 and $\mathbf{2 3}$ ) when comparing to their analogues $\mathbf{2}$ and $\mathbf{1 7}$ (Table 1). The effect of oxygen atoms in 22 can be seen in Figure 1 where its bridged carbon atoms are positively charged while in $\mathbf{1 6}$ the corresponding bridged carbon atoms are negatively charged. Likewise, it is expected that $\mathbf{2 2}$ and $\mathbf{2 3}$ have smaller aromaticity with respect to their respective analogues $\mathbf{1 6}$ and $\mathbf{1 7}$.
The dicationic diazo-analogues $\mathbf{1 9}$ and $\mathbf{2 0}$ have very small delocalization indexes values among bridged atoms in comparison to $\mathbf{1 6}$ and $\mathbf{1 7}$, respectively. The species $\mathbf{1 9}$ and 20 probably do not have tridimensional aromaticity since their delocalization indexes among bridged atoms are equivalent with those from neutral analogues $\mathbf{4}$ and $\mathbf{5}$, respectively (Table 1 ). However, in $\mathbf{1 9}$, there exists a bond between bridged carbon atoms, while in $\mathbf{2 0}$ no similar bond exists between bridged silicon atoms. The diazo-oxyderivative $\mathbf{2 4}$ has the smallest delocalization indexes values within the dicationic aromatic oxy-analogues $(\mathbf{2 2}, \mathbf{2 3}$ and 24) and it is probably the least aromatic one.

The dicationic 21, containing one boron, one nitrogen and two carbon bridged atoms, has delocalization indexes among bridged atoms higher than those from $\mathbf{1 9}$ and $\mathbf{2 0}$. Then, $\mathbf{2 1}$ is probably more aromatic than $\mathbf{1 9}$ and $\mathbf{2 0}$, as it is confirmed by its NICS value in Table 2 .

The molecular graphs of $\mathbf{1 4}$ and $\mathbf{1 9}$ show interesting aspects. In 14 (Figure 2a) both $\sigma$ bonds between silicon atoms are broken after its optimization. Moreover, the delocalization indexes among $\mathrm{R}^{1}, \mathrm{R}^{3}, \mathrm{R}^{5}$ and $\mathrm{R}^{7}$ are not uniform. In 19 (Figure $2 b$ ) the two $\mathrm{sp}^{2}$ carbon atoms make a bond after geometry optimization as it can be seen in the delocalization index between them $(\mathrm{DI}=0.836$, in Table 1$)$ and the density of this bond critical point ( $\rho=0.21$ a.u.). All other delocalization indexes among $\mathrm{R}^{1}, \mathrm{R}^{3}, \mathrm{R}^{5}$ and $\mathrm{R}^{7}$ are just little higher than those from 4 , which agrees with the small NICS value of $\mathbf{1 9}$ (Table 2). Nevertheless, no bond is made between silicon atoms in $\mathbf{2 0}$.

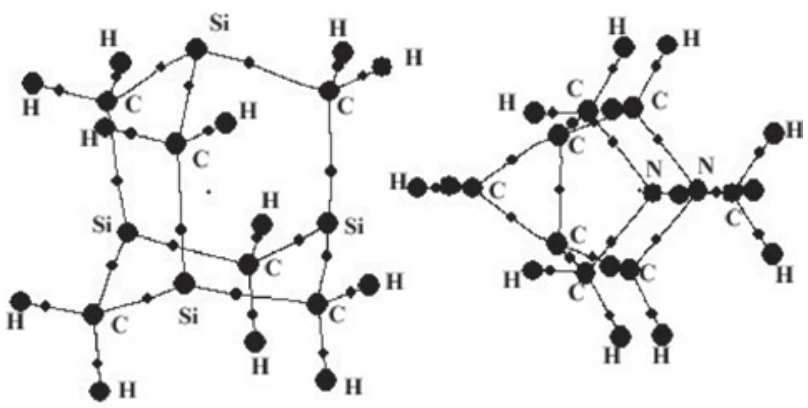

(a)

(b)

Figure 2. Molecular graph from AIM of the species 14 (a) and 19 (b).

Interestingly, in the neutral compound 29, electropositive boron atoms attract electrons from bridgehead carbon atoms and generate reasonable delocalization indexes among bridged carbon and boron atoms. By comparing with compound 6, where DI's among bridged carbon and boron atoms is only 0.033 , it is possible to see how effectively boron atoms distribute electrons from bridged carbon atoms in $\mathbf{2 9}$ (Table $1)$. This can be verified by comparing $\mathrm{C}-\mathrm{C}$ atomic distances between $28(1.562 \AA)$ and $29(2.110 \AA)$ in Figure 3. The latter has a much larger distance which represents a delocalization 

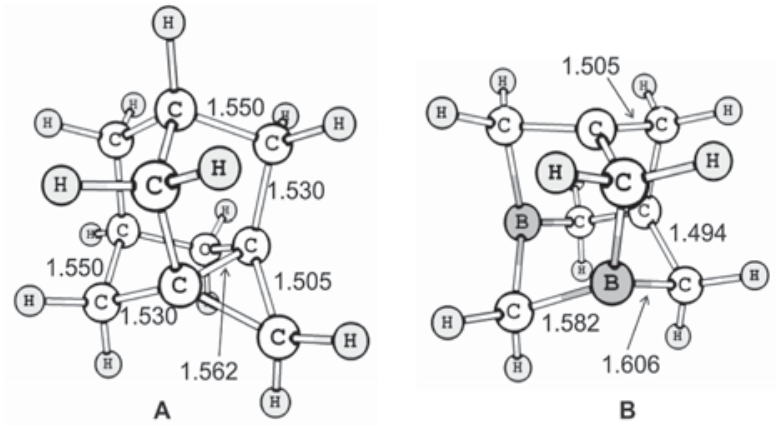

Figure 3. Selected atomic and interatomic distances $(\AA)$ of the species 28 (A) and 29 (B).

of this $\sigma \mathrm{C}-\mathrm{C}$ bond. Then, 29 can be regarded as tridimensional aromatic species, as supported by its NICS value of -38.80 (Table 2). Although less effectively, boron atoms also provoke distribution of the electrons of the bridged silicon in 30. Optimized structures of the species $1,2,4,6,7,10,11,13$, $15,16,17,19,21,22,25$ and 26 are shown in the electronic supplementary information.

Another important analysis from AIM theory is the Laplacian of the charge density, $\nabla^{2} \rho$. It is defined as the sum of the three principal curvatures of the function at each point of the space. However, it is a convenient convention to use the negative of the Laplacian, L(r), rather than the Laplacian itself. Then, $\mathrm{L}(\mathrm{r})=-\nabla^{2} \rho$. The density is a locally concentrated in those regions where $L(r)>0$, since $\nabla^{2} \rho(r)<0$ when $\rho(r)$ is a local maximum. Likewise, the density is a locally depleted in those regions where $\mathrm{L}(\mathrm{r})<0$, since $\nabla^{2} \rho(r)>0$ when $\rho(r)$ is a local minimum. ${ }^{24}$

In Figure 4, it is depicted the negative of the Laplacian curves in a plane that passes through three bridged carbon atoms of $\mathbf{1 0}$ and 16. It is possible to see that the negative of the Laplacian distribuition region in the 1,3-dehydro-5,7adamantanediyl dication (16) where $\mathrm{L}(\mathrm{r})<0$ encompasses the three bridged carbons atoms. This represents a uniform charge density distribution over these atoms and indicates

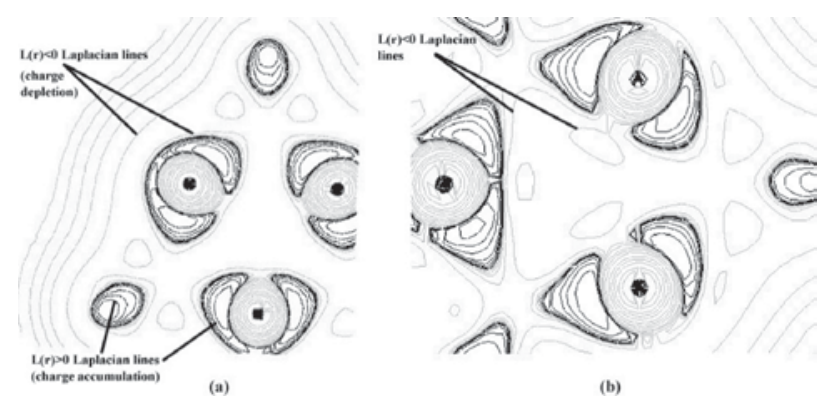

Figure 4. Contour maps of the Laplacian distribution of the electronic charge density for the 1,3-dehydro-5-7-adamantanediyl dication (a) and 1,3 adamantyl dication (b) in the plane that contains three bridged carbon atoms. The gray curves are related to charge depletion, while the black lines are charge concentration. an interaction among them. In case of the 1,3 adamantyl dication (10), there exists no $\mathrm{L}(\mathrm{r})<0$ Laplacian distribution region encompassing the three bridged carbons and it indicates absence of significant interaction among them.

The AIM study of the diamantyl dications $\mathbf{3 3}$ and $\mathbf{3 4}$ provides a different electronic nature between them (see Figure 5). The former was prepared and characterized but the latter was not obtained. ${ }^{26}$ In the 4,9-diamantyl dication 33 there are three considerable delocalization indexes (DI= $0.117)$ linking each positively charged carbon atom (C1 and $\mathrm{C} 8$ ) and its corresponding bridgehead carbon atoms (C2 to $\mathrm{C} 7$ ). In the 1,6-diamantyl dication 34, there exists just one considerable delocalization index $(\mathrm{DI}=0.168)$ and two delocalization indexes immediately inferior ( $\mathrm{DI}=0.085)$ For 33, the delocalization indexes are uniform and for 34 the delocalization indexes are not.

In Figure 6, one can see that the atomic distances between each positively charge carbon atom and its vicinal carbon atom is uniform in $\mathbf{3 3}$ (1.462 $\AA$ ) and non-uniform

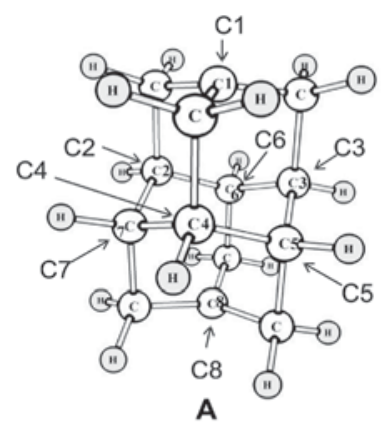

$\mathrm{C} 1-\mathrm{C} 2=0.117 \quad \mathrm{C} 1-\mathrm{C} 5=0.015$ $\mathrm{C} 1-\mathrm{C} 3=0.117 \quad \mathrm{C} 1-\mathrm{C} 6=0.015$ $\mathrm{C} 1-\mathrm{C} 4=0.117 \quad \mathrm{C} 1-\mathrm{C} 7=0.015$

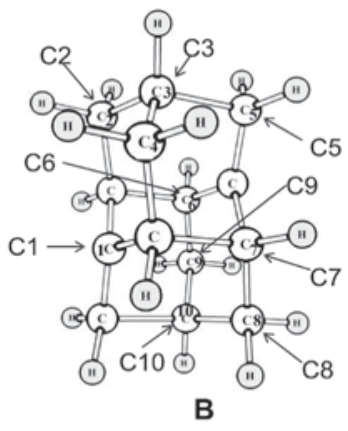

$\mathrm{C} 1-\mathrm{C} 2=0.048 \quad \mathrm{C} 1-\mathrm{C} 6=0.085$ $\mathrm{C} 1-\mathrm{C} 3=0.015 \quad \mathrm{C} 1-\mathrm{C} 7=0.085$

$\mathrm{C} 1-\mathrm{C} 4=0.048 \quad \mathrm{C} 1-\mathrm{C} 8=0.022$

$\mathrm{C} 1-\mathrm{C} 5=0.006 \quad \mathrm{C} 1-\mathrm{C} 9=0.023$
Figure 5. Delocalization indexes between positively charge carbon atoms and non-vicinal carbon atoms in the species 33 (A) and 34 (B)."

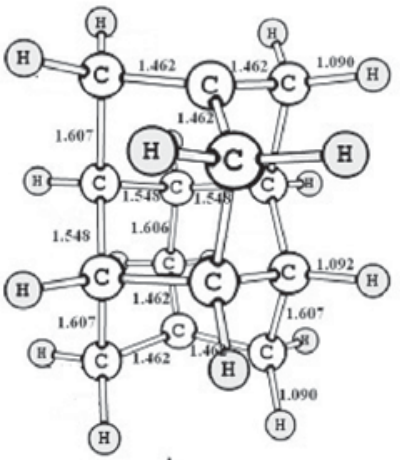

A

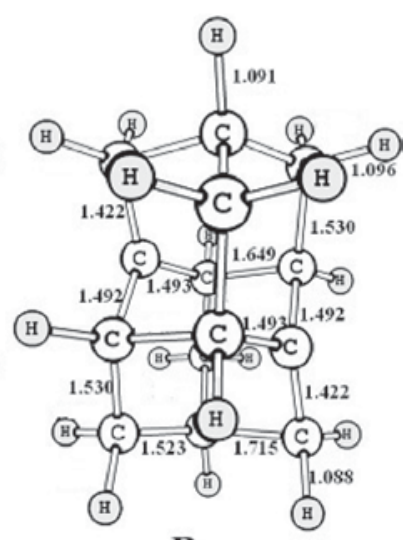

B
Figure 6. Atomic distances $(\AA)$ of the species 33 (A) and 34 (B). 
in 34 (1.492, 1.493 and $1.422 \AA$ ). These results are in consonance with the uniformity of the delocalization indexes of each corresponding species mentioned above.

We proposed the $\mathrm{D}_{3} \mathrm{BIA}$ index which is based on the density in the ring, the degeneracy and the delocalization index of atoms in the ring ${ }^{21}$ and it is inspired to the modern VB idea about aromaticity as mentioned before. (see Electronic supplementary information).

The rationale on the index $\mathrm{D}_{3}$ BIA was influenced by modern VB studies on the aromaticity and the particularities of some aromatic compounds. ${ }^{21}$ The similarities of the results between AIM and spin coupled wave function (SC) encouraged us to use the former since it provides important and complementary information. The coherence between the AIM and SC can be noticed from their results for benzene (see Electronic supplementary information).

There are some multi-center delocalization indexes proposed to measure aromaticity, for example, the six-center delocalization index ${ }^{27}(\mathrm{SCI})$ and Fermi hole density delocalization inde ${ }^{28}$ (FDDH). However, it is important to emphasize that these multicenter indexes are based on $\mathrm{MO}$ approach of aromaticity, i.e., the delocalization of orbitals in the aromatic molecules. ${ }^{29}$ On the other hand, the D3BIA index is inspired to a different approach - the spin-coupled (SC) of the modern VB theory. The focus of SC study on the aromaticity is not the delocalization of the molecular orbital over the aromatic molecule since it was demonstrated that $\pi$ single-electron orbitals are localized in each $\mathrm{sp}^{2}$ carbon atom in the case of benzene. ${ }^{19}$ The focus of modern VB study on aromaticity is the degeneracy and the overlap of the single-electron orbitals and these are the VB paremeters that inspired the formula of D3BIA index in atoms in molecules theory.

The electron density in the aromatic site can be understood in terms of the density in the region involving the bridged atoms. Then, the density factor is the density in the center of the cage structure and the magnitude of the delocalization indexes among bridged atoms or mean delocalization index $\overline{D I}$.
The degree of the degeneracy $(\delta)$ is derived from the energies of the atomic basins of the bridged atoms (from AIM theory).

The uniformity of delocalization indexes among bridged atoms is another important electronic feature found in the tridimensional aromatic species (Table 1).

The proposed $\mathrm{D}_{3} \mathrm{BIA}$ formula is:

$D_{3} B I A=\rho(3,+3) \cdot(\overline{\mathrm{DI}}) \cdot D I U \cdot \delta$

The degree of degeneracy is regarded to be maximum $(\delta=1)$ when energy difference is smaller than 0.009 a.u.

The AIM provides a delocalization index for each bond between vicinal atoms. ${ }^{19}$ The mean delocalization index (DI) can be related to the magnitude of the single-electron states interaction (or overlap).

The delocalization index uniformity (DIU) among bridged atoms is given by equation 2 :

$\mathrm{DIU}=100-\frac{100 \sigma}{(\overline{\mathrm{DI}})}$

Where $\sigma$ is mean deviation and (DI) is mean DI of the ring.

In Table 2, one can see the $\mathrm{D}_{3} \mathrm{BIA}$ values for all aromatic and non-aromatic species (1 to $\mathbf{3 2}$ ). It was also performed NICS of the species 1 to 32. Their NICS values are depicted in Table 2 and it is calculated from a probe (berkelium) in the center of adamantyl cage. ${ }^{7,5}$ Since all the studied species do not have $\pi$ orbitals, the use of a dissected NICS, e.g. CMO-NICS method, is unnecessary. ${ }^{30}$ Because the species $\mathbf{3 3}$ and $\mathbf{3 4}$ are structurally different from other species, their $\mathrm{D}_{3}$ BIA's have not been calculated.

From the 1,3-dehydro-5,7-dichloro-adamantane, the 1,3-dichloro-adamantane, the 1,3-dehydro-5-chloroadamantane and their analogues (Scheme 3 ) it is possible to calculate the stability of the species 10-12, 16, 18, 21-23 and 25-27 by means of the equations 3 and 4 .

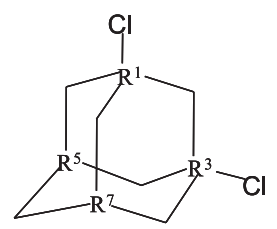

35. $\mathrm{R}^{1}=\mathrm{R}^{3}=\mathrm{CCl} ; \mathrm{R}^{5}=\mathrm{R}^{7}=\mathrm{CH}$ 36. $\mathrm{R}^{1}=\mathrm{R}^{3}=\mathrm{SiCl} ; \mathrm{R}^{5}=\mathrm{R}^{7}=\mathrm{SiH}$ 37. $\mathrm{R}^{1}=\mathrm{R}^{3}=\mathrm{SiCl} ; \mathrm{R}^{5}=\mathrm{R}^{7}=\mathrm{CH}$

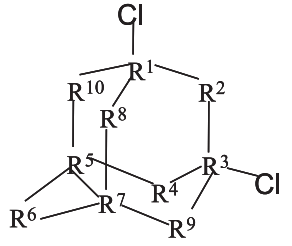

38. $\mathrm{R}^{1}=\mathrm{R}^{3}=\mathrm{CCl} ; \mathrm{R}^{5}=\mathrm{R}^{7}=\mathrm{C}$

39. $\mathrm{R}^{1}=\mathrm{R}^{3}=\mathrm{Si} ; \mathrm{R}^{5}=\mathrm{R}^{7}=\mathrm{Si}$

40. $\mathrm{R}^{1}=\mathrm{R}^{3}=\mathrm{SiCl} ; \mathrm{R}^{5}=\mathrm{R}^{7}=\mathrm{C}$

41. $\mathrm{R}^{1}=\mathrm{R}^{3}=\mathrm{CCl} ; \mathrm{R}^{5}=\mathrm{N}^{+} ; \mathrm{R}^{7}=\mathrm{B}^{-}$

42. $\mathrm{R}^{2}=\mathrm{R}^{4}=\mathrm{R}^{8}=\mathrm{R}^{9}=\mathrm{R}^{10}=\mathrm{O}$ $\mathrm{R}^{1}=\mathrm{R}^{3}=\mathrm{CCl} ; \mathrm{R}^{5}=\mathrm{R}^{7}=\mathrm{C} ; \mathrm{R}^{6}=\mathrm{CH}_{2}$

43. $\mathrm{R}^{2}=\mathrm{R}^{4}=\mathrm{R}^{8}=\mathrm{R}^{9}=\mathrm{R}^{10}=\mathrm{O}$ $\mathrm{R}^{1}=\mathrm{R}^{3}=\mathrm{SiCl} ; \mathrm{R}^{5}=\mathrm{R}^{7}=\mathrm{Si} ; \mathrm{R}^{6}=\mathrm{CH}_{2}$

Scheme 3.

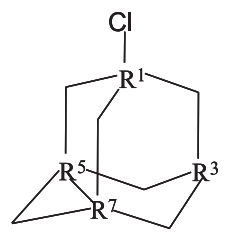

44. $\mathrm{R}^{1}=\mathrm{CCl} ; \mathrm{R}^{3}=\mathrm{CH} ; \mathrm{R}^{5}=\mathrm{R}^{7}=\mathrm{C}$

45. $\mathrm{R}^{1}=\mathrm{SiCl} ; \mathrm{R}^{3}=\mathrm{SiH} ; \mathrm{R}^{5}=\mathrm{R}^{7}=\mathrm{Si}$

46. $\mathrm{R}^{1}=\mathrm{SiCl} ; \mathrm{R}^{3}=\mathrm{SiH} ; \mathrm{R}^{5}=\mathrm{R}^{7}=\mathrm{C}$ 
Table 2. Density of $(3,+3)$ critical point $[\rho(3,+3)]$, mean delocalization index $(\overline{D I})$, delocalization index uniformity (DIU) among bridged atoms, degree of degeneracy $(\delta), \mathrm{D}_{3}$ BIA, NICS and free energy variation of the dehalogenation reaction $\left(\Delta \mathrm{G}_{(}\right.$ ) of the species $\mathbf{1}$ to $\mathbf{3 2}$

\begin{tabular}{|c|c|c|c|c|c|c|c|}
\hline Entry & $\rho(3,+3) / a u$ & $\overline{D I}$ & DIU & $\delta$ & $\mathrm{D}_{3} \mathrm{BIAx} 10^{2}$ & NICS & $\begin{array}{c}\Delta \mathrm{G}_{(\text {dehalogenation })} / \\
\left(\mathrm{kcal} \mathrm{mol}^{-1}\right)\end{array}$ \\
\hline 1 & 0.012 & 0.039 & 100 & 1 & 4.68 & -0.38 & - \\
\hline 2 & 0.007 & 0.007 & 100 & 1 & 0.49 & -0.63 & - \\
\hline 3 & 0.009 & 0.018 & 64.24 & 0.5 & 0.52 & -0.90 & - \\
\hline 4 & 0.014 & 0.070 & 82.38 & 0.5 & 4.04 & 2.38 & - \\
\hline 5 & 0.010 & 0.044 & 43.18 & 0.5 & 0.95 & 1.78 & - \\
\hline 6 & 0.015 & 0.034 & 88.99 & 0.5 & 2.27 & -12.62 & - \\
\hline 7 & 0.018 & 0.026 & 76.73 & 0.5 & 1.79 & 3.27 & - \\
\hline 8 & 0.012 & 0.006 & 91.23 & 0.5 & 0.33 & 0.24 & - \\
\hline 9 & 0.017 & 0.053 & 76.45 & 0.5 & 3.44 & & \\
\hline 10 & 0.020 & 0.135 & 86.17 & 0.5 & 11.63 & -19.31 & 384.97 \\
\hline 11 & 0.011 & 0.021 & 83.99 & 0.5 & 0.97 & -6.42 & 397.59 \\
\hline 12 & 0.013 & 0.055 & 86.49 & 0.5 & 3.09 & -9.07 & 419.74 \\
\hline 13 & 0.044 & 0.330 & 0.32 & 1 & 0.46 & 1.91 & - \\
\hline 14 & 0.012 & 0.100 & 82.19 & 0.5 & 4.93 & 23.53 & - \\
\hline 15 & 0.020 & 0.076 & 70.59 & 0.5 & 5.36 & -12.70 & - \\
\hline 16 & 0.046 & 0.280 & 100 & 1 & 128.8 & -46.47 & 355.34 \\
\hline 17 & 0.021 & 0.096 & 99.48 & 1 & 20.05 & -36.35 & 365.37 \\
\hline 18 & 0.024 & 0.149 & 91.67 & 0.5 & 16.39 & -29.08 & 375.27 \\
\hline 19 & 0.023 & 0.207 & 1.39 & 0.5 & 0.33 & -10.90 & - \\
\hline 20 & 0.009 & 0.026 & 45.02 & 0.5 & 0.53 & -0.87 & - \\
\hline 21 & 0.033 & 0.175 & 68.63 & 0.5 & 19.82 & -37.52 & 364.20 \\
\hline 22 & 0.053 & 0.169 & 84.56 & 0.5 & 37.87 & -36.81 & 513.71 \\
\hline 23 & 0.015 & 0.114 & 83.38 & 0.75 & 10.69 & -19.55 & 491.86 \\
\hline 24 & 0.030 & 0.182 & 14.19 & 0.5 & 3.87 & -6.31 & - \\
\hline 25 & 0.031 & 0.240 & 29.52 & 0.75 & 16.47 & -29.76 & 110.83 \\
\hline 26 & 0.014 & 0.087 & 21.84 & 0.75 & 1.99 & -15.93 & 127.35 \\
\hline 27 & 0.018 & 0.124 & 25.70 & 0.5 & 2.87 & -22.30 & 131.17 \\
\hline 28 & 0.023 & 0.190 & 16.79 & 0.5 & 3.67 & -9.90 & - \\
\hline 29 & 0.030 & 0.135 & 54.76 & 0.5 & 11.09 & -38.80 & - \\
\hline 30 & 0.021 & 0.079 & 37.13 & 0.5 & 3.08 & -29.32 & - \\
\hline 31 & 0.027 & 0.066 & 43.94 & 0.75 & 5.87 & -27.85 & - \\
\hline 32 & 0.015 & 0.082 & 64.24 & 0.75 & 5.93 & -8.58 & - \\
\hline
\end{tabular}

$\mathrm{Cl}-\mathrm{R}-\mathrm{CL} \rightarrow \mathrm{R}^{+2}+2 \mathrm{Cl}^{-}$

$\mathrm{R}=$ Adamantyl or its analogues; or 1,3-dehydroadamantyl or its analogues

$\mathrm{R}-\mathrm{Cl} \rightarrow \mathrm{R}^{+}+\mathrm{Cl}^{-}$

$\mathrm{R}=1,3$-Dehydroadamantyl or its analogues

The energetics of all studied species are depicted in Electronic supplementary information. The free energy variation values of the dehalogenation of the species 10-12, 16-18, 21-23 and 25-27 are shown in Table 2.

From Table 2 one can see that the non-aromatic species $\mathbf{1}$ to $\mathbf{1 2}$ have the same electronic characteristics: small density in $(3,+3)$ critical point (the density in centre of the cage structure) and small values of mean delocalization index among bridged atoms. One exception is the 1,3-adamantyl dication $\mathbf{1 0}$, for not having two electrons distributed among bridged carbon atoms and still having a reasonable mean delocalization index value $(0.135)$ and density in $(3,+3)$ critical point $(0.020$ a.u. $)$. 
All non-aromatic species (1 to $\mathbf{1 5}$ and $\mathbf{2 8}$ to $\mathbf{3 2}$ ) have low D BIA. However, $\mathbf{1 0}$ and $\mathbf{2 9}$ have reasonable $\mathrm{D}_{3} \mathrm{BIA}^{\prime} \mathrm{s}$ (Table 2) because their density in $(3,+3)$ critical point and their values of mean delocalization index among bridged atoms are not small. There exists an apparent tendency for interaction between bridged atoms. In the 1,3-adamantyl dication 10, there is no available electrons as it happens in its parent the 1,3-dehydro-5,7-adamantanediyl dication 16, but it uses sigma electron density to generate interaction among its bridged atoms. On the other hand, 29 has two electrons between bridged carbon atoms but it has no positive charge as the aromatic species 16. However, its bridged electropositive boron atoms draw the electron density towards them and this provokes a reasonable distribution of electron density among all bridged atoms (Tables 1 and 2). Then, 29 has tridimensional aromaticity.

The species $\mathbf{1 9}$ and $\mathbf{2 0}$ are not regarded aromatic ones since their $\mathrm{D}_{3}$ BIA's are very low. The species $\mathbf{1 9}$ has quite small delocalization index uniformity and $\mathbf{2 0}$ has small density in $(3,+3)$ critical point and small values of mean delocalization index among bridged atoms (Table 2).

In spite of not having tridimensional aromaticity the 1,3-dehydro-7-adamantyl cation $\mathbf{2 5}$ has a high $\mathrm{D}_{3} \mathrm{BIA}$ (16.47). The species 25 has a characteristic planar homoaromaticity.

When analyzing its planar aromaticity, by exclusion of methine bridged carbon and the density in $(3,+3)$ critical point, it is considered a three-membered planar ring among the other bridged carbons where its $\overline{D I}=0.410$, its DIU $=100$ and its $\delta=1$. Then, its planar $\mathrm{D}_{3}$ BIA is higher than that shown in Table 2.

Free energies of dehalogenation reactions of 10-12, 16-18, 21-23 have been used to confirm the coherence of the $\mathrm{D}_{3} \mathrm{BIA}$ values (Table 2). Despite there is no good correlation between them, it is possible to verify that the smaller the free energy of dehalogenation the higher is the $\mathrm{D}_{3} \mathrm{BIA}$. The smallest $\Delta \mathrm{G}_{\text {(dehalogenation) }}$ value is for the 1,3-dehydro-5-7-adamantanediyl dication 16. $\Delta \mathrm{G}_{\text {(dehalogenation) }}$ values of $\mathbf{1 0}$ to $\mathbf{1 2}$ are higher for than those from 16, 17, 18 and $\mathbf{2 1}$. All of these $\Delta \mathrm{G}$ values fit to their relation with $\mathrm{D}_{3} \mathrm{BIA}$. For example, $\mathbf{1 0}$, with $\mathrm{D}_{3} \mathrm{BIA}=11.63$, has $\Delta \mathrm{G}_{\text {(dehalogenation) }}$ value $(384.97 \mathrm{kcal}$ $\left.\mathrm{mol}^{-1}\right)$ higher than those from the species $18\left(\mathrm{D}_{3} \mathrm{BIA}=16.39\right.$, $\left.\Delta \mathrm{G}_{\text {(dehalogenation) }}=375.27 \mathrm{kcal} \mathrm{mol}^{-1}\right)$ and $21\left(\mathrm{D}_{3} \mathrm{BIA}=19.82\right.$, $\Delta \mathrm{G}_{\text {(dehalogenation) }}=364.20 \mathrm{kcal} \mathrm{mol}^{-1}$ ). However, $\Delta \mathrm{G}$ value of $\mathbf{2 2}$ does not fit in the analyzed group, according to its D $_{3}$ BIA. Moreover, one can see that NICS values somewhat support all of these tendencies described above (Table 2).

Within monocationic species 25 to 27, there seems to be a reasonable relation between $\mathrm{D}_{3} \mathrm{BIA}$ and $\Delta \mathrm{G}_{\text {(dehalogenation) }}$ values, where the 1,3-dehydro-7-adamantyl cation $25\left(\mathrm{D}_{3} \mathrm{BIA}=16.47\right)$ has the smallest $\Delta \mathrm{G}_{\text {(dehalogenation) }}$ value (Table 2).

\section{Conclusions}

The electronic interaction among bridged atoms is decisive in tridimensional aromaticity, along with uniformity of the delocalization index involving bridged atoms and their degeneracy. The density in the center of the cage $[(3,+3)$ critical point $]$ and the mean delocalization index values among bridged atoms are distinguished between tridimensional non-aromatic and aromatic species: non-aromatic species have small $\rho(3,+3)$ and $\overline{D I}$ values while aromatic ones have high $\rho(3,+3)$ and $\overline{D I}$ values. The degeneracy of the bridged atoms, the uniformity and the magnitude of their delocalization indexes are the electronic features that distinguish the dications $\mathbf{1 0}$ and 16. However, the 1,9 diamantyl dication $\mathbf{1 0}$ has tridimensional aromaticity as well as the 1,3-dehydro5,7-diboroadamantane 29.

The positive charge is mainly distributed among the hydrogen atoms and the bridged atoms remain negatively charged in the dicationic and monocationic aromatic species.

\section{Supplementary Information}

This supplementary material shows the atoms in molecules theory, the rationale on $\mathrm{D}_{3} \mathrm{BIA}$, benzene and resonance, delocalization index and basis set dependence, the quantum atom, similarities between NICS and D BIA, comparison of the delocalization indexes between MP2 and B3LYP computed energy values of the species $\mathbf{1}$ to 46, optimized structures of the species $1,2,4,6,7,10$, 11, 13, 15, 16, 17, 19, 21, 22, 25 and 26 and their bond lengths, and internal coordinates of optimized structures. This material is available free of charge at http://jbcs.sbq. org.br, as PDF file.

\section{Acknowledgments}

Authors thank CNPq, CAPES and FAPERJ for financial support.

\section{References}

1. Olah, G. A.; Comisarow, M. B.; Cupas, C. A.; Pittman, C. U.; J. Am. Chem. Soc. 1965, 87, 2998; Schleyer, P. v. R.; Fort, R. C. Jr.; Watts, W. E.; Comisarow, M. B.; Olah, G. A.; J. Am. Chem. Soc. 1964, 86, 4195.

2. Rasul, G.; Olah, G. A.; Prakash, G. K. S.; Proc. Natl. Acad. Sci. U. S. A. 2004, 101, 10868.

3. Olah, G. A.; Prakash, G. K. S.; Shi, J. G.; Krishnamurthy, V. V.; Mateescu, G. D.; Liang, G.; Sipos, G.; Buss, V.; Gund, J. M.; Schleyer, P. v. R.; J. Am. Chem. Soc. 1985, 107, 2764. 
4. Prakash, G. K. S.; Krishnamurthy, V. V.; Arvanaghi, M.; Olah, G. A.; J. Org. Chem. 1985, 50, 3985.

5. Bremer, M.; Schleyer, P. v. R.; Schoetz, K.; Kaush, M.; Schindler, M.; Angew. Chem. Int. Ed. 1987, 26, 761.

6. Fryem, C. L.; Klosowski, J. M.; Weyenberg, D. R.; J. Am. Chem. Soc. 1970, 92, 6379 .

7. Okazaki, T.; Galembeck, S. E.; Laali, K. K.; J. Org. Chem. 2002, 67, 8721; Chen, Z.; Hirsch, A.; Nagase, S.; Thiel, W.; Schleyer, P. v. R.; J. Am. Chem. Soc. 2003, 125, 15507.

8. Fokin, A. A.; Kiran, B.; Bremer, M.; Yang, X.; Jiao, H.; Schleyer, P. V. R.; Schreiner, P. R.; Chem. Eur. J. 2000, 6, 1615.

9. Olah, G. A.; Rasul, G.; Prakash, G. K. S.; J. Org. Chem. 2000, $65,5956$.

10. Prakash, G. K. S.; Bae, C.; Kroll, M.; Olah, G. A.; J. Fluorine Chem. 2002, 117, 103; Pincock, R.E.; Torupka, E. J.; J. Am. Chem. Soc. 1969, 91, 4593.

11. Scott, W. B.; Pincock, R. E.; J. Am. Chem. Soc. 1973, 95, 2040.

12. Olah, G. A.; Reddy, V. P.; Rasul, G.; Prakash, G. K. S.; J. Am. Chem. Soc. 1999, 121, 9994.

13. Gaussian 03. Revision B.04; Frisch, M. J.; Trucks, G. W.; Schlegel, H. B.; Scuseria, G. E.; Robb, M. A.; Cheeseman, J. R.; Zakrzewski, V. G.; Montgomery, J. A. Jr.; Vreven, T.; Kudin, K. N.; Burant, J. C.; Millam. J. M.; S. S. Iyengar.; Tomasi, J. ; Barone, V.; Mennucci, B.; Cossi, M.; Scalmani, G.; Rega, N.; Petersson, G. A.; Nakatsuji, H.; Hada, M.; Ehara, M.; Toyota, K.; Fukuda, R.; Hasegawa, J.; Ishida, M.; Nakajima, T.; Honda, Y.; Kitao, O.; Nakai, H.; Klene, M.; Li, X.; Knox, J. E.; Hratchian, H. P.; Cross, J. B.; Adamo, C.; Jaramillo, J.; Gomperts, R.; Stratmann, R. E.; Yazyev, O.; Austin, A. J.; Cammi, R.; Pomelli, C.; Ochterski, J. W.; Ayala, P. Y.; Morokuma, K.; Voth, G. A.; Salvador, P.; Dannenberg, J. J.; Zakrzewski, V. G.; Dapprich, S.; Daniels, A. D.; Strain, M. C.; Farkas, O.; Malick, D. K; Rabuck, A. D.; Raghavachari, K.; Foresman, J. B.; Ortiz, J. V.; Cui, Q.; Baboul, A. G.; Clifford, S.; Cioslowski, J.; Stefanov, B. B.; Liu, G.; Liashenko, A.; Piskorz, P.; Komaromi, I.; Martin, R. L.; Fox, D. J.; Keith, T.; Al-Laham, M. A.; Peng, C. Y.; Nanayakkara, A.; Challacombe, M.; Gill, P. M. W.; Johnson, B.; Chen, W.; Wong, M. W.; Gonzalez, C.; Pople, J. A.; Gaussian. Inc. Pittsburgh P. A., 2003.

14. Becke, A. D.; J. Chem. Phys. 1993, 98, 1372; Becke, A. D.; J. Chem. Phys. 1993, 98, 5648.

15. Lee, C.; Yang, W.; Parr, R. G.; Phys. Rev. B: Condens. Matter Mater. Phys. 1998, 37, 785.

16. Hehre, W. J.; Radom, L.; Schleyer, P. v. R.; Pople, J. A.; Wiley: New York, 1986.
17. Biegler-König, F.; Schönbohm, J.; AIM2000, Version 2.0, 2002.

18. Schleyer, P. v. R.; Maeker, C.; Dransfeld, A.; Jiao, H.; Hommes, N. J. R. v. E.; J. Am. Chem. Soc. 1996, 118, 6317.

19. Cooper, D. L.; Gerratt, J.; Raimondi, M.; Nature 1986, 323, 699; Cooper, D. L.; Gerratt, J.; Raimondi, M.; Chem. Rev. 1991, 91, 929.

20. Nascimento, M. A. C.; Barbosa, A. G. H.; Adv. Top. in Theor. Chem. Phys. 2003, 247.

21. Resonance is only possible when the superposition of the hybrids can recover the full symmetry of the system. Resonance is related to degeneracy or near-degeneracy effects. Degeneracy may be due to the existence of symmetry groups that commute with hamiltonian. For more information see McWeeny, R.; Symmetry: An Introduction to Group Theory and its Applications, Dover: Mineola, 2002; Löwdin, P.O.; Rev. Mod. Phys. 1967, 39, 259.

22. Nascimento, M. A. C.; Barbosa, A. G. H. In Fundamental World of Quantum Chemistry; Brändas, E. J.; Kryachko, E. S., eds.; Kluwer: Dordrech, 2003, Vol. 1.

23. Bader, R. F. W.; Chem. Rev. 1991, 91, 893.; Bader, R. F. W.; Acc. Chem. Res. 1985, 18, 9; Popelier, P.; Atoms in Molecules, $1^{\text {st }}$ ed., Prentice Hall: Manchester, 2000.

24. Fradera, X.; Austen, M. A.; Bader, R. F. W.; J. Phys. Chem. A 1999, 103, 304; Merino, G.; Vela, A.; Heine, T.; Chem. Rev. 2005, 105, 3812.

25. Firme, C. L.; Galembeck; S. E.; Antunes, O. A. C.; Esteves, P. M.; J. Braz. Chem. Soc. 2007, 18, 1397.

26. Olah, G. A.; Prakash, G. K. S.; Shih, J. G.; Krishnamurthy, V. V.; Mateescu, G. D.; Liang, G.; Sipos, G.; Buss, V.; Gund, T. M.; Schleyer, P. v. R.; J. Am. Chem. Soc. 1985, 107, 2764.

27. Bultinck, P.; Ponec, R.; Van Damme, S.; J. Phys. Org. Chem. 2005, 18, 706.

28. Matta, C.; Hernández-Trujillo, J.; J. Phys. Chem. A 2003, 107, 7496.

29. Bultinck, P.; Rafat, M.; Ponec, R.; Gheluwe, B. V.; Carbó-Dorca, R.; Popelier, P.; J. Phys. Chem. A 2006, 110, 7642

30. Heine, T.; Schleyer, P. v. R.; Corminboeuf, C.; Seifert, G.; Reviakine, R.; Weber, J.; J. Phys. Chem. A 2003, 107, 6470; Corminboeuf, C.; Heine, T.; Seifert, G.; Schleyer, P. v. R.; Phys. Chem. Chem. Phys. 2004, 6, 273; Chen, Z.; Wannere, C. S.; Corminboeuf, C.; Puchta, R.; Schleyer, P. v. R.; Chem. Rev. $\mathbf{2 0 0 5}, 105,3842$.

Received: May 31, 2007 Published on the web: January 29, 2008 


\title{
Electronic Nature of the Aromatic Adamantanediyl Ions and its Analogues
}

\author{
Caio L. Firme, O. A. C. Antunes and Pierre M. Esteves*
}

\author{
Instituto de Química, Universidade Federal do Rio de Janeiro, Av. Athos da Silveira Ramos, 149, CT Bloco A, \\ $6^{\circ}$ andar, Cidade Universitária, Ilha do Fundão, 21941-909 Rio de Janeiro-RJ, Brazil
}

\section{Atoms in Molecules (AIM) Theory}

Bader's Atoms in molecules (AIM) theory ${ }^{1}$ is based on the condition defining the quantum subsystem in terms of a property of the gradient vector of the charge density $(\nabla \rho)$. The quantum condition of the subsystem states that the surface bounding the subsystem shall not be crossed by any gradient vectors of $\rho$. Since the gradient vector of $\rho$ always points at the direction of greatest increase in $\rho$, it must always be perpendicular to lines of constant density. Let $\mathrm{n}$ be a unit vector normal to the surfaces, if the scalar product $\nabla \rho . n$ vanishes, then $\nabla \rho$ has no component through the surface. This surface, where $\nabla \rho . n=0$, is called zero-flux surface, and it is the borderline between subsystems. The point, within the zero-flux surface, where gradient vectors are pointed at, and therefore where $\nabla \rho=0$, is called a bond critical point.

Inside the nucleus charge density exhibits local maxima. Outside the nucleus, charge density decreases as it moves away from the nucleus in any direction. Knowing that gradient path is a junction of gradient vectors at a given direction, then all the gradient paths within a subsystem will terminate at the nucleus. A nucleus is said to behave as an attractor in the gradient vector field.

The critical points ${ }^{1}$ are classified according to their spectrum, which is a set of eigenvalues of the Hessian matrix $\nabla \nabla \rho$. The Hessian is a matrix of second derivatives of some function with respect to all possible coordinates. The eigenvalue equation of $\nabla \nabla \rho$ has three solutions $\left(\lambda_{1}, \lambda_{2}, \lambda_{3}\right)$ corresponding to each eigenvector $\vec{u} \mathrm{i}_{(\mathrm{i}=1,2.3)}$ which coincides with the principal axes of curvature. The Laplacian of the electron density $\left(\nabla^{2} \rho\right)$ is the sum of the eigenvalues of the Hessian, or $\nabla^{2} \rho=\lambda_{1}+\lambda_{2}+\lambda_{3}$. The nuclear attractor is denoted by $(3,-3)$ because it is a maximum in all the principal axes. The bond critical point (BCP) is denoted by $(3,-1)$ because it is a minimum in the direction of the nucleus but it is a maximum in another main direction. The ring critical point $(\mathrm{RCP})$ is denoted by $(3,+1)$, where is minimum in two principal axes.

\footnotetext{
*e-mail: pesteves@iq.ufrj.br
}

The Laplacian of the charge density, is defined as the sum of the three principal curvatures of the function at each point of the space (equation 1), which is also the trace of the Hessian of the density at the corresponding point. ${ }^{2}$

$\nabla^{2} \rho(r)=\frac{\partial^{2} \rho(r)}{\partial x^{2}}+\frac{\partial^{2} \rho(r)}{\partial y^{2}}+\frac{\partial^{2} \rho(r)}{\partial z^{2}}$

It is a convenient convention of using the negative of the Laplacian, L(r), rather than the Laplacian itself. Then, $\mathrm{L}(\mathrm{r})=-\nabla^{2} \rho$. The density is a locally concentrated in those regions where $L(r)>0$, since $\nabla^{2} \rho(r)<0$ when $\rho(r)$ is a local maximum. Likewise, the density is a locally depleted in those regions where $\mathrm{L}(\mathrm{r})<0$, since $\nabla^{2} \rho(\mathrm{r})>0$ when $\rho(\mathrm{r})$ is a local minimum.

\section{Rationale on D BIA}

The coherence between AIM and SCVB can be noticed from AIM results of benzene. The DI between carbon atoms in benzene is 1.39. Since DI between carbon atoms in ethane is 1.0 , it is established that $0.39 \mathrm{e}$. from $\pi$ system is delocalized in each $\mathrm{C}-\mathrm{C}$ bond of benzene ring. This means that $0.61 \mathrm{e}$. from each $2 \mathrm{p}_{\mathrm{z}}$ electron is localized in each carbon atom in benzene. This result matches with spin coupled (SC) one where a $2 p_{z}$ electron of benzene is localized and distorted symmetrically towards neighboring carbon atoms on each side. ${ }^{3}$ Moreover, Gerratt and co-workers ${ }^{4}$ remarked that distortion effects of $\mathrm{C}\left(2 \mathrm{p}_{\mathrm{z}}\right)$ orbitals are not larger than those in $\mathrm{C}-\mathrm{C} \pi$ bonds in conjugated systems. From AIM calculations, DI's in hexatriene are 1.74 (for double bond) and 1.14 (for single bond). That brings another convergence of results between SC and AIM theories since it shows that delocalization in acyclic conjugated systems is greater than that in benzene.

Pauling and Wheland ${ }^{5}$ stated that benzene is represented by a linear combination of five independent canonical structures. This view is emphasized by SC theory, ${ }^{6,8}$ where spin coupling two electrons allows the description of the different possible resonance structures and generates the stability of aromatic systems. 
From a more rigorous quantum mechanical standpoint, ${ }^{8}$ benzene has no resonance ${ }^{9}$ since there is not intersection of degenerate point group states. Resonance is only possible when the superposition of the hybrids can recover the full symmetry of the system. Resonance is related to degeneracy or near-degeneracy effects. Degeneracy may be due to the existence of symmetry groups that commute with hamiltonian. ${ }^{9}$

It means that benzene ( $D_{6 \mathrm{~h}}$ symmetry) cannot be related to Kekulé $\left(\mathrm{D}_{3 \mathrm{~h}}\right.$ symmetry) or Dewar $\left(\mathrm{D}_{2 \mathrm{~h}}\right)$ structures since it is forbidden by point group symmetry rules. ${ }^{10}$ In this case, benzene stability is ascribed to maximum overlap among six degenerate single-electron states. ${ }^{11}$

\section{Benzene and Resonance}

Resonance is related to degeneracy or near-degeneracy effects. Degeneracy may be due to the existence of symmetry groups that commute with hamiltonian. ${ }^{9}$ The eigenfunctions of the exact hamiltonian must transform as irreducible representations of the commuting symmetry groups. When a given group has degenerate representations, some or all eigenstates of the hamiltonian of the system will reflect its degeneracy.

The real Hilbert space is always partitioned into a direct sum of subspaces, each representing a different energy eigenvalue of the spectrum of the hamiltonian operator. The direct product decomposition is the mathematical tool to analyze the symmetry of the allowed individual states. It is related to the "ascent in symmetry" method ${ }^{12}$ for decomposition of tensor spaces in independent parts and justified by the Littlewood-Richardson rules. ${ }^{13}$ These rules define the only allowed decompositions of a tensor space (e.g. point group space), providing us with the possible symmetries of the resonance hybrids, which reproduce the total symmetry of the system. Only invariant subgroups of some larger group can accommodate coherent states.

The possible forms of decomposing $\mathrm{D}_{6 \mathrm{~h}}$ point group in direct products ${ }^{14}$ are:

$\mathrm{D}_{6 \mathrm{~h}}=\mathrm{D}_{6} \otimes \mathrm{Ci}, \mathrm{D}_{6} \otimes \mathrm{C}_{\mathrm{s}}, \mathrm{C}_{6 \mathrm{v}} \otimes \mathrm{C}_{\mathrm{s}}$

The ground state of benzene is not degenerate, and there is no theoretical or experimental evidence of a neardegenerate electronic state with same geometry as the ground state. If there is no intersection of degenerate point group states one cannot follow the symmetry descent path in this case. The only alternative would be that of an accidental symmetry, but this is not possible since there is not direct product decomposition ${ }^{8}$ from $\mathrm{D}_{3 \mathrm{~h}}$ (Kekulé structure) and $\mathrm{D}_{2 \mathrm{~h}}$ (Dewar structure).
However, in SC study of benzene, Gerratt and coworkers ${ }^{15}$ stated that spin coupling two electrons (within same $\mathrm{D}_{6 \mathrm{~h}}$ symmetry) allows the description of the different possible resonance structures and generates the stability of aromatic systems.

Then, existence of resonance in benzene depends on the rigor of theory applied to it. By spin coupling $\omega$ electrons, within same $\mathrm{D}_{6 \mathrm{~h}}$ symmetry in $\mathrm{SC}$, it is possible to associate the obtained stability with resonance of hybrid structures. ${ }^{15}$ Otherwise, benzene molecule cannot be represented by "hybrids" of symmetries $\mathrm{D}_{3 \mathrm{~h}}$ and $\mathrm{D}_{2 \mathrm{~h}}$ since it is forbidden by point group symmetry rules. ${ }^{8}$

\section{Delocalization Index and Basis Set Dependence}

As stated by Popelier: ${ }^{16}$ "since AIM charges are obtained directly from electron density, they depend less on the basis set used compared with methods which separate charges on the Hilbert space of the basis set." In addition, atomic charge is related to charge transfer between atomic basins. And since the delocalization index is related to the interaction between atomic basins, we can assume that the rough value of the delocalization index is not so sensitive to a basis set.

\section{The Quantum Atom}

Bader's AIM theory defines atomic subsystems within a molecular system from its density matrix calculated by a specific $a b$ initio or density functional method. Then, AIM divides the molecular system into atomic subsystems. ${ }^{17}$ AIM is based on quantum subsystem in terms of a property of gradient vector of charge density $(\nabla \rho)$. In AIM it is possible to define all average properties of an atom. The definition of these properties is reduced to the quantummechanical definitions of the corresponding properties for a isolated atom. The summation of the atomic values of a given property over all atoms of the molecule yields the average property for the molecule.

Therefore, AIM provides the energy of an atom inside a molecule. The total energy of an atom is the sum of the kinetic energy and the potential energy. The kinetic energy an atom is obtained by the kinetic energy density. This means that the kinetic energy is evaluated locally at a point just like the electron density. Integration over the kinetic energy density gives the integrated kinetic energy over a given volume. There are two types of kinetic energies denoted by $\mathrm{K}(\mathrm{r})$ and $\mathrm{G}(\mathrm{r})$, defined in equations 2 and 3 , respectively. ${ }^{16}$

$K(r)=-\frac{1}{4} N \int d \tau^{\prime}\left[\psi^{*} \nabla^{2} \psi+\psi \nabla^{2} \psi^{*}\right]$ 


$$
G(r)=\frac{1}{2} N \int d \tau^{\prime} \nabla \psi^{*} . \nabla \psi
$$

where $\mathbf{r}$ represents the coordinates of a position vector and $N \int d \tau^{\prime}$ summarizes the one-electron integration mode.

After some mathematical treatment, it is possible to obtain the following relation between $\mathrm{K}(\mathrm{r})$ and $\mathrm{G}(\mathrm{r})$ :

$$
K(r)=G(r)-\frac{1}{4} \nabla^{2} \rho(r)
$$

If we integrate equation 4 over the full space then we obtain that $\mathrm{K}$ (full space) $=\mathrm{G}$ (full space) since the last term of equation 4 vanishes. That is a consequence of Gauss'divergence theorem (equation 5).

$$
\iiint_{\Omega} d V \nabla^{2} \rho=\iiint_{\Omega} d V \nabla \cdot \nabla \rho=\iint_{S} d S \nabla \rho \cdot \mathbf{n}=0
$$

where $\mathrm{S}$ is an interatomic surface (IAS) for which $\nabla \rho . n=0$.

Then, the kinetic energy of an atom is unambiguously defined and it is commonly called T(full space), as defined bellow (equation 6).

$T(\Omega)=K(\Omega)=G(\Omega)$

The potential energy is obtained from kinetic energy by using the virial theorem. The roots of the concept of virial theorem lie in the development of thermodynamics in the nineteenth century, when it was realized that internuclear forces in real gases induce deviations in ideal gas behavior. Soon after the mathematical formalism of quantum mechanics was established, Slater derived the quantum analogue of the classical virial theorem (equation 7).

$$
2 \int d \tau \psi^{*} \hat{T} \psi=-\int d \tau \psi^{*}\left(\sum_{j} \hat{r}_{j} \hat{F}_{j}\right) \psi
$$

In equation 7 , the sum runs over all the particles (both electrons and nuclei) and the integration is over the total space in which the system exists. The right-hand side of equation 7 is the potential energy of the system of particles because it is the expectation value of the position and force operators. We conclude that the kinetic energy of a system is always related to its potential energy.

Within the Born-Oppenheimer approximation, equation 7 becomes the molecular virial theorem shown in equation 8 . The term on the right-hand side of equation 7 falls into two terms in equation 8 , namely the expectation value of the electronic potential energy and a term depending on the forces on the nuclei.

$$
2 \int d \tau \psi_{e l}^{*} \hat{T} \psi_{e l}=-\int d \tau \psi_{e l}^{*} \hat{V}_{e l} \psi_{e l}-\sum_{\alpha} r_{\alpha} \frac{\partial E}{\partial r_{\alpha}}
$$

where $\psi_{\mathrm{el}}$ is the electronic wave function, $\hat{V}_{e l}$ is the electronelectron repulsion and electron-nucleus attraction potential energy operator, $\mathrm{E}$ is the total energy of the molecule and $r_{\alpha}$ are the nuclear coordinates.

For a geometrically optimized molecule, all forces on the nuclei vanish and the term $\sum_{\alpha} r_{\alpha} \frac{\partial E}{\partial r_{\alpha}}$ in the molecular virial theorem vanishes. By simply restricting the integrals of the expectation values in equation 8 to the atomic subspace rather than full space, we obtain a relation between potential energy and kinetic energy inside an atomic basin (equation 9).

$$
2 T(\Omega)=-V(\Omega)
$$

Historically, the roots of the theory of AIM lie in the observation that the kinetic energy of a molecular fragment bound by a zero-flux surface in $\nabla \rho$ could be transferred from one molecule to another. ${ }^{18}$ The further development of AIM has been driven by the desire to formulate an atomic virial theorem which could render the atom into an energetically meaningful fragment.

Table S1 illustrates the calculation of atomic energies of all atoms in methanal. ${ }^{16}$

Table S1. The energies of the atoms in methanal (in a.u.)

\begin{tabular}{lc}
\hline Atom & $\mathrm{E} / \Omega$ \\
\hline $\mathrm{C}$ & -37.4332 \\
$\mathrm{O}$ & -75.9020 \\
$\mathrm{H}$ & -0.6052 \\
Total & -114.5456 \\
\hline
\end{tabular}

\section{Similarities Between NICS and $\mathrm{D}_{3}$ BIA}

Table S2. $\mathrm{D}_{3}$ BIA and NICS of some aromatic compounds

\begin{tabular}{lcc}
\hline Compound & $\mathrm{D}_{3} \mathrm{BIA} \times 10^{3}$ & NICS \\
\hline Benzene & 10 & -8.06 \\
Pyridine & 8.1 & -6.8 \\
Pyrazine & 6.6 & -5.34 \\
Tryazine 1,4,5 & 2.57 & -3.77 \\
Tryazine 1,3,5 & 4.4 & -4.07 \\
Cycloheptatriene & & -6.29 \\
cation & 4.0 & \\
Anthracene & & -7.46 \\
(central ring) & 6.0 & \\
\hline
\end{tabular}


Optimized Structures of the Species 1, 2, 4, 6, 7, 10, 11, 13, 15, 16, 17, 19, 21, 22, 25 and 26 and their Bond Lengths.

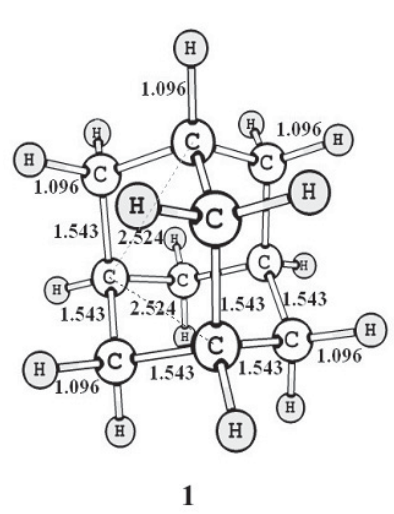

(1)

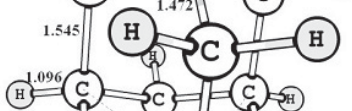

(1).1966 (C) $\Rightarrow$ (C) $\Rightarrow$ (C)

(1) $=$ (1.096 (i) (1)

(ii)

4

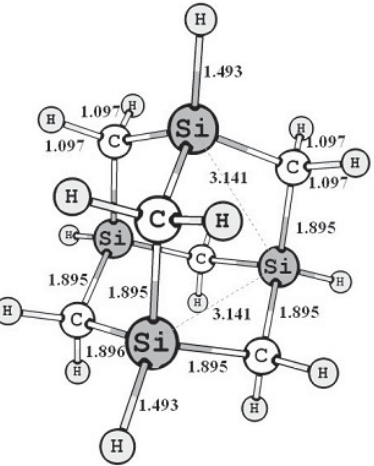

2

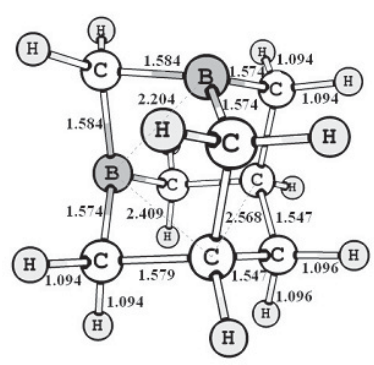

6
(B) 81.092

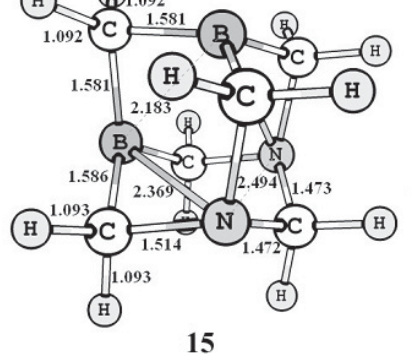

15
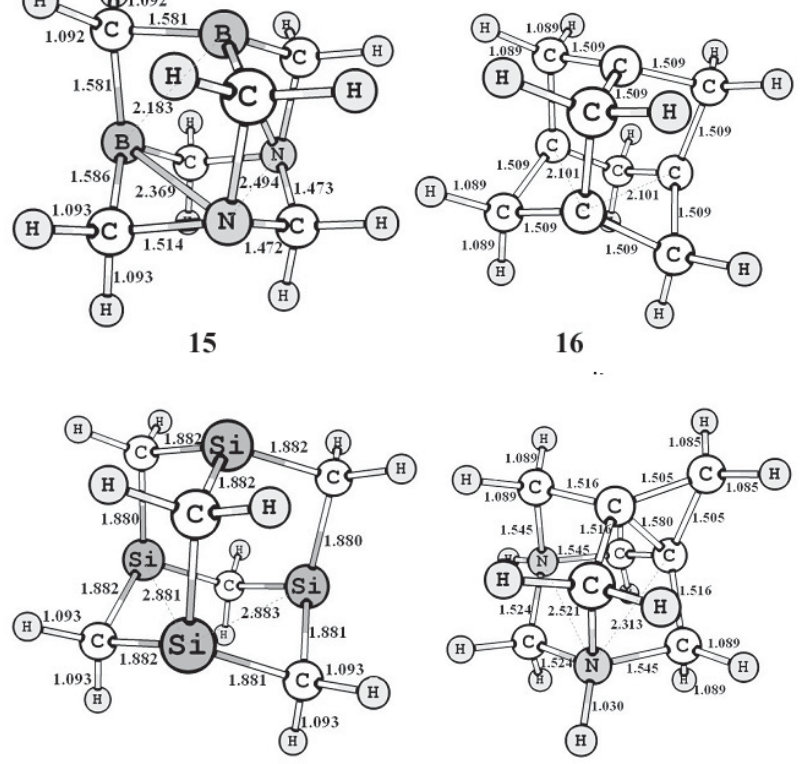

17

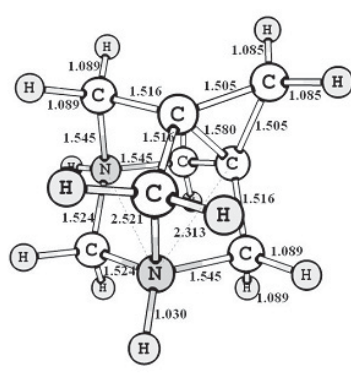

19

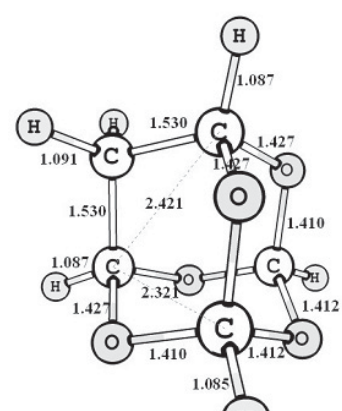

(H)

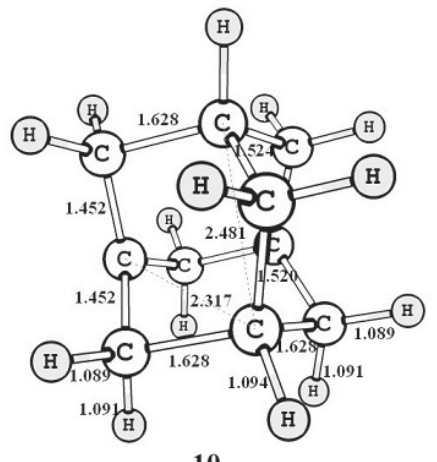

10

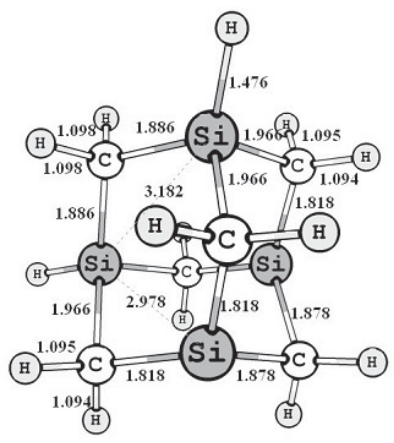

11

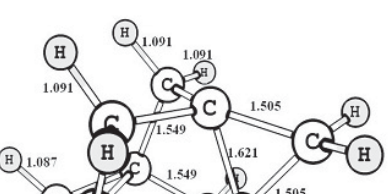

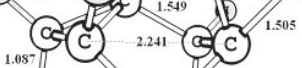

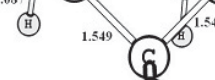

B)

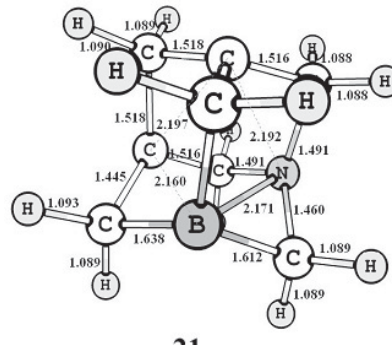

21
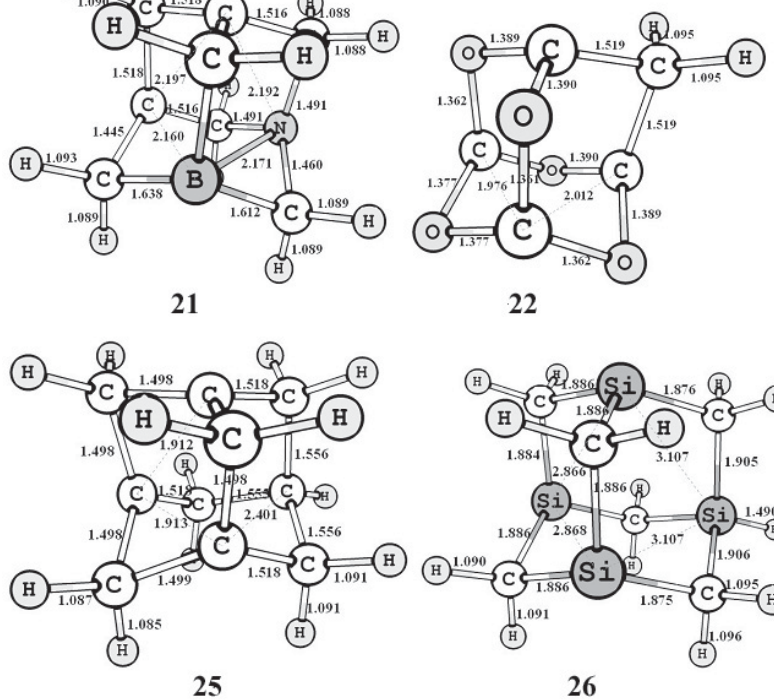
Table S3. Computed energy values of the species $\mathbf{1}$ to $\mathbf{4 6}$

\begin{tabular}{|c|c|c|c|}
\hline Entry & H / Hartree & $\mathrm{S} /\left(\mathrm{cal} \mathrm{mol}^{-1} \mathrm{~K}^{-1}\right)$ & G / Hartree \\
\hline 1 & -390.573479 & 76.061 & -390.609618 \\
\hline 2 & -1396.321449 & 102.685 & -1396.370238 \\
\hline 3 & -893.423903 & 92.051 & -893.467640 \\
\hline 4 & -422.649468 & 80.494 & -422.687713 \\
\hline 5 & -925.484387 & 91.575 & -925.527897 \\
\hline 6 & -394.942092 & 84.722 & -394.982346 \\
\hline 7 & -570.269011 & 77.465 & -570.305817 \\
\hline 8 & -1576.414808 & 91.994 & -1576.458517 \\
\hline 9 & -602.098577 & 78.616 & -602.135930 \\
\hline 10 & -388.606446 & 82.909 & -388.645838 \\
\hline 11 & -1394.438573 & 101.325 & -1394.486715 \\
\hline 12 & -891.504397 & 91.702 & -891.547967 \\
\hline 13 & -387.979284 & 80.885 & -388.017715 \\
\hline 14 & -1393.769261 & 105.313 & -1393.819298 \\
\hline 15 & -394.942074 & 84.529 & -394.982236 \\
\hline 16 & -387.391465 & 80.422 & -387.429676 \\
\hline 17 & -1393.241920 & 99.677 & -1393.289280 \\
\hline 18 & -890.337262 & 89.828 & -890.379942 \\
\hline 19 & -421.951412 & 80.549 & -421.989684 \\
\hline 20 & -926.067598 & 91.992 & -926.111307 \\
\hline 21 & -390.818886 & 81.693 & -390.857701 \\
\hline 22 & -566.780090 & 77.250 & -566.816794 \\
\hline 23 & -1573.080219 & 91.742 & -1573.123808 \\
\hline 24 & -601.173938 & 79.207 & -601.211572 \\
\hline 25 & -388.457228 & 81.045 & -388.495736 \\
\hline 26 & -1394.223763 & 101.974 & -1394.272214 \\
\hline 27 & -891.349536 & 91.400 & -891.392963 \\
\hline 28 & -389.308420 & 80.737 & -389.346781 \\
\hline 29 & -361.653560 & 83.127 & -361.693056 \\
\hline 30 & -864.545577 & 92.935 & -864.589734 \\
\hline 31 & -365.084394 & 84.080 & -365.124343 \\
\hline 32 & -543.464416 & 91.392 & -543.507839 \\
\hline 33 & -543.454349 & 92.974 & -543.498523 \\
\hline 34 & -389.692107 & 82.262 & -389.731192 \\
\hline 35 & -1309.851695 & 94.995 & -1309.896831 \\
\hline 36 & -2315.701894 & 117.704 & $-2315.757819^{a}$ \\
\hline 35 & -1812.803290 & 107.493 & -1812.854364 \\
\hline 37 & -1308.588536 & 94.510 & -1308.633441 \\
\hline 39 & -2314.435291 & 118.636 & -2314.491658 \\
\hline 40 & -1811.564830 & 106.588 & -1811.615473 \\
\hline 41 & -1312.029887 & 96.184 & -1312.075588 \\
\hline 42 & -1488.230438 & 89.453 & -1488.272940 \\
\hline 43 & -2494.494200 & 107.219 & -2494.545143 \\
\hline 44 & -848.949457 & 87.661 & -848.991107 \\
\hline 45 & -1854.741158 & 111.039 & -1854.793916 \\
\hline 46 & -1351.873878 & 98.644 & -1351.920747 \\
\hline $\mathrm{Cl}^{-}$ & -460.301367 & 36.586 & -460.318750 \\
\hline
\end{tabular}

aasis set 6-311++G(d,p)

Comparison of Delocalization Indexes Between MP2 and B3LYP

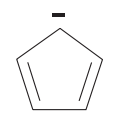

DI $(\mathrm{C}-\mathrm{C})=1.379(\mathrm{~B} 3 \mathrm{LYP})$ DI $(\mathrm{C}-\mathrm{C})=1.364(\mathrm{MP} 2)$

\section{Internal Coordinates of Optimized Structures}

Species 1

Charge $=0$ Multiplicity $=1$

C, $0,1.4538527257,-0.0000000002,1.0280291215$

$\mathrm{H}, 0,1.4777495417,-0.0000000002,2.1241313909$

$\mathrm{H}, 0,2.4952334612,-0.0000000003,0.685191833$

C, $0,0.7285249617,1.261842248,0.5151449408$

$\mathrm{H}, 0,1.2452114793,2.156769548,0.8804974811$

C, $0,0.7285249614,-1.2618422482,0.5151449408$

$\mathrm{H}, 0,1.2452114788,-2.1567695483,0.8804974811$

C, $0,-0.7269263632,-1.2590733938,1.0280291212$

$\mathrm{H}, 0,-0.7388747715,-1.2797686438,2.1241313905$

$\mathrm{H}, 0,-1.247616731,-2.1609355657,0.6851918324$

C, $0,-0.7269263629,1.259073394,1.0280291212$

$\mathrm{H}, 0,-1.2476167305,2.160935566,0.6851918324$

$\mathrm{H}, 0,-0.7388747712,1.2797686439,2.1241313905$

C, $0,-1.4570499234,0.0000000002,0.5151449404$

$\mathrm{H}, 0,-2.4904229585,0.0000000003,0.8804974805$

C, $0,-1.4538527257,0.0000000002,-1.0280291215$

$\mathrm{H}, 0,-1.9864915016,-0.8811669218,-1.4046616119$

H, $0,-1.9864915013,0.8811669222,-1.4046616119$

C, $0,0.7269263632,1.2590733938,-1.0280291212$

$\mathrm{H}, 0,1.7563586907,1.2797686436,-1.4046616113$

$\mathrm{H}, 0,0.2301328119,2.1609355658,-1.4046616116$

C, $0,0.7269263629,-1.259073394,-1.0280291212$

H, $0,1.7563586903,-1.2797686441,-1.4046616113$

$\mathrm{H}, 0,0.2301328114,-2.1609355659,-1.4046616116$

C, $0,0.0000000003,0 .,-1.5454348219$

$\mathrm{H}, 0,0.0000000004,0 .,-2.6414924428$

Species 2

Charge $=0$ Multiplicity $=1$

C, $0,0.3309365799,-0.0000057743,0.2409960137$

$\mathrm{H}, 0,0.3447185424,-0.0001367713,1.3375767505$

H, $0,1.3790158076,-0.0000224094,-0.0816308457$

C, $0,-2.3270485686,-1.5351006846,0.2070352342$

$\mathrm{H}, 0,-2.354642093,-1.5609532464,1.3029869641$

H, $0,-2.844874889,-2.4383817973,-0.1373459519$

C, $0,-2.3268811455,1.5353545108,0.2074481865$

H, $0,-2.8446331383,2.4387848969,-0.1366519002$ 
$\mathrm{H}, 0,-2.3544495774,1.5608834121,1.3034085709$ C,0,-3.1819722706,0.0005007121,-2.3086530586 H,0,-3.7132156957,-0.8775908858,-2.6951569277 H, $0,-3.7130996173,0.8787665901,-2.6949215454$ C,0,-0.5225005491,1.535449125,-2.2773869725 $\mathrm{H}, 0,0.5107807057,1.5607235336,-2.6438150473$ H, $0,-1.0099942468,2.4391257903,-2.6624155028$ C, $0,-0.5225929626,-1.5346941482,-2.2777667516$ H, $0,0.5107145451,-1.5598472136,-2.644133601$ $\mathrm{H}, 0,-1.010048567,-2.4382597575,-2.6631008381$ Si, $0,-0.5259663764,1.5706888655,-0.3830251718$ $\mathrm{H}, 0,0.1711096937,2.789325876,0.124249023$ Si, $0,-3.2469899947,0.0002584865,-0.4152359673$ $\mathrm{H}, 0,-4.6606347619,0.0002812524,0.0641708732$ Si,0,-0.5261261512,-1.5704525642,-0.3834191633 $\mathrm{H}, 0,0.1708067515,-2.789298869,0.1235489751$ Si,0,-1.401091567,0.0004883583,-2.9581732472 $\mathrm{H}, 0,-1.3824413292,0.0006563689,-4.4507792304$

Species 3

Charge $=0$ Multiplicity $=1$ C, $0,0.3925971753,-0.0000160839,0.2859839583$ $\mathrm{H}, 0,0.3949768083,-0.0001589627,1.3813310605$ $\mathrm{H}, 0,1.4364992315,-0.0000212484,-0.045349412$ C, $0,-2.3649939338,-1.2872070985,0.1104364631$ $\mathrm{H}, 0,-2.4787399278,-1.2569845715,1.2000467067$ $\mathrm{H}, 0,-2.9325370309,-2.1606220147,-0.2334927019$ C, $0,-2.3648702896,1.2874741581,0.1107785692$ $\mathrm{H}, 0,-2.9323349831,2.1610334543,-0.232912863$ H, $0,-2.4786103399,1.2569708588,1.2003818228$ C,0,-2.9692592105,0.0002457483,-0.5194508685 $\mathrm{H}, 0,-4.0441450443,0.000268385,-0.2984033547$ $\mathrm{C}, 0,-2.8474188554,0.000446043,-2.066059506$ $\mathrm{H}, 0,-3.3810048114,-0.8761787407,-2.4532673253$ $\mathrm{H}, 0,-3.3809121668,0.8772310897,-2.4530321386$ C, $0,-0.6270582254,1.2872930667,-2.2839515131$ H, $0,0.3741194892,1.2551866368,-2.7287478493$ $\mathrm{H}, 0,-1.1276728184,2.1618743263,-2.7170058316$ C, $0,-0.6271775972,-1.2865592237,-2.284284324$ $\mathrm{H}, 0,0.374003746,-1.2544260003,-2.7290706337$ H,0,-1.1278701617,-2.1609815422,-2.7175693656 C,0,-1.4146963501,0.0004520967,-2.6636467233 $\mathrm{H}, 0,-1.5382021955,0.0005989138,-3.7539486232$ $\mathrm{Si}, 0,-0.5506062956,-1.4892174594,-0.4012216199$ $\mathrm{Si}, 0,-0.5504683958,1.4894489858,-0.4008360402$ $\mathrm{H}, 0,0.0202304427,2.8036727378,0.0138333475$ H,0,0.0199626977,-2.8036063746,0.0131025468
Species 4

Charge $=0$ Multiplicity $=1$

C,0,-0.000671011,-0.005653273,-0.0046293704 $\mathrm{H}, 0,0.0230824187,-0.0324727264,1.0904333967$ H,0,1.037397622,-0.0366865286,-0.3535319547 C, $0,-0.7148021438,1.2700016934,-0.5045620575$ H, $0,-0.2151673422,2.1643176524,-0.1144702673$ C, $0,-2.090121894,-1.1826987169,-0.0146278892$ $\mathrm{H}, 0,-2.0920443903,-1.1813405559,1.078875598$ $\mathrm{H}, 0,-2.5963668154,-2.0887243804,-0.3590792156$ C, $0,-2.1781914037,1.2139200379,-0.0102261052$ $\mathrm{H}, 0,-2.7457454393,2.0817565505,-0.3636280545$ $\mathrm{H}, 0,-2.217670208,1.2226655984,1.084635339$ C, $0,-2.8639825166,-0.0203477628,-1.9638316027$ H, $0,-3.404612975,-0.9133270677,-2.2966441448$ H,0,-3.4295935579,0.8509322723,-2.3119241082 C, $0,-0.7111365226,1.2687469789,-2.0471789537$ $\mathrm{H}, 0,0.317256019,1.2990306846,-2.4273285198$ H,0,-1.2209791633,2.1606937014,-2.4312864543 C, $0,-0.6868385889,-1.2401943103,-1.9584285358$ H,0,0.3530236226,-1.2689054554,-2.302043111 H,0,-1.1656542159,-2.1681407972,-2.2899942839 C, $0,-1.4264672594,-0.0099688113,-2.5303844338$ $\mathrm{H}, 0,-1.4483097952,-0.053594425,-3.6254916234$ $\mathrm{N}, 0,-0.6944266784,-1.2174289996,-0.4828171715$ $\mathrm{N}, 0,-2.8474123228,-0.0120636331,-0.4877836445$

Species 5

Charge $=0$ Multiplicity $=1$

C, $, 0,-0.0047409372,-0.0000000005,-0.0025900496$ $\mathrm{H}, 0,-0.0029312772,-0.0000000005,1.0929568337$ $\mathrm{H}, 0,1.0396892558,-0.0000000007,-0.3328969445$ C, $0,-2.7824242651,-1.2408857961,-0.2165963029$ $\mathrm{H}, 0,-2.9541567301,-1.1839316079,0.8630542985$ H,0,-3.3891889705,-2.0807222064,-0.5762517905 C, $0,-2.782424265,1.2408857959,-0.2165963033$ $\mathrm{H}, 0,-3.3891889698,2.0807222065,-0.5762517921$ H, $0,-2.9541567306,1.1839316085,0.863054298$ C, $0,-3.1726471321,-0.0000000005,-2.3061425037$ H, $0,-3.6928053994,-0.8851940976,-2.6842775398$ H, $0,-3.6928053997,0.8851940963,-2.6842775403$ C, $0,-1.0634248925,1.2406024723,-2.5814880322$ $\mathrm{H}, 0,-0.0890270442,1.1823587065,-3.0771360977$ H, $0,-1.5912701155,2.0811374503,-3.0479617296$ C, $0,-1.0634248925,-1.2406024732,-2.5814880321$ $\mathrm{H}, 0,-0.089027044,-1.1823587071,-3.077136097$ $\mathrm{H}, 0,-1.5912701152,-2.0811374512,-3.04796173$ $\mathrm{N}, 0,-3.3104653117,-0.0000000002,-0.8430863254$ $\mathrm{N}, 0,-1.8230315772,-0.0000000005,-2.891039445$ 
Si, $0,-0.9459796324,1.4932590504,-0.6893596166$ $\mathrm{H}, 0,-0.3891582029,2.8185371547,-0.284302923$ Si,0,-0.9459796328,-1.4932590512,-0.6893596165 H, $0,-0.3891582034,-2.8185371555,-0.284302923$

Species 6

Charge $=0$ Multiplicity $=1$ C,0,0.1552060994,0.0000148161,0.1121862883 $\mathrm{H}, 0,0.1173074784,-0.0001243276,1.2036514854$ $\mathrm{H}, 0,1.1805026193,0.0000211278,-0.264023778$ C, $0,-2.2076089656,-1.2953511095,0.0440664558$ $\mathrm{H}, 0,-2.2693514926,-1.2792472564,1.1362507596$ $\mathrm{H}, 0,-2.7418828727,-2.1776392183,-0.3198633481$ C, $0,-2.2074917682,1.2956177894,0.0444062962$ $\mathrm{H}, 0,-2.7416837995,2.1780491997,-0.3192953644$ $\mathrm{H}, 0,-2.2692364977,1.2792355994,1.1365863683$ C, $0,-2.9081316675,0.0002392173,-0.5246670404$ C, $0,-2.8512167995,0.0004415326,-2.0702902208$ $\mathrm{H}, 0,-3.3797865814,-0.8793930956,-2.4539804655$ H, $0,-3.3797095871,0.8804237785,-2.4537478345$ C, $0,-0.6412478384,1.2959855009,-2.1122075522$ $\mathrm{H}, 0,0.3783464046,1.2798000725,-2.508524806$ $\mathrm{H}, 0,-1.1528551135,2.1782340583,-2.5072651422$ C,0,-0.6413660312,-1.2952875975,-2.1125501979 $\mathrm{H}, 0,0.378230886,-1.2790904786,-2.508860434$ $\mathrm{H}, 0,-1.1530517318,-2.1773846507,-2.5078445295$ C, $0,-1.398844897,0.0004471076,-2.6028483278$ B, $0,-0.7655683722,1.1019991887,-0.5555576137$ B, $0,-0.7656669052,-1.1017084081,-0.5558461208$ $\mathrm{H}, 0,-3.9529253933,0.0002437105,-0.1964272317$ H,0,-1.4095638244,0.0005931085,-3.697915519

Species 7

Charge $=0$ Multiplicity $=1$

C,0,0.020294489,0.0000000005,0.0144463801

$\mathrm{H}, 0,0.0117524416,0.0000000017,1.1055666045$

$\mathrm{H}, 0,1.0490052857,-0.0000000003,-0.3492275759$

$\mathrm{O}, 0,-2.0864742065,1.1659975665,-0.0532258855$

$\mathrm{O}, 0,-2.086474208,-1.1659975647,-0.0532258848$

$\mathrm{O}, 0,-2.7252924221,0.0000000007,-1.9410580574$

$\mathrm{O}, 0,-0.7319825404,1.166062285,-1.9547923505$

$\mathrm{O}, 0,-0.7319825413,-1.166062284,-1.9547923499$

C, $0,-2.7214833343,0.0000000015,-0.5288066526$

$\mathrm{H}, 0,-3.7477135162,0.0000000014,-0.1778926953$

C,0,-1.3893037538,0.,-2.3992349474

$\mathrm{H}, 0,-1.3928208582,0 .,-3.4837939472$

C, $0,-0.7413680279,-1.2104218096,-0.5284008423$

C, $0,-0.7413680253,1.2104218111,-0.528400844$

$\mathrm{H}, 0,-0.3319635456,-2.1741392378,-0.2366243691$
H,0,-0.3319635437,2.1741392395,-0.2366243702

Species 8

Charge $=0$ Multiplicity $=1$

C,0,-0.034557691,0.,-0.0231669637

$\mathrm{H}, 0,-0.0288574632,-0.0000000001,1.0721110167$ $\mathrm{H}, 0,1.0052267584,0.0000000002,-0.3672669699$ $\mathrm{O}, 0,-2.54649347,1.3263686386,-0.1746154398$ $\mathrm{O}, 0,-2.5464934698,-1.3263686388,-0.1746154401$ $\mathrm{O}, 0,-3.2980520048,0.0000000002,-2.3457877369$ $\mathrm{O}, 0,-0.9986174289,1.3252105227,-2.3513281951$ $\mathrm{O}, 0,-0.9986174288,-1.3252105224,-2.3513281953$ Si, $0,-0.9569018485,-1.5103163014,-0.6830384506$ Si, $0,-0.9569018488,1.5103163014,-0.6830384503$ Si,0,-1.7646176061,0.0000000002,-3.0091410691 $\mathrm{Si}, 0,-3.4200211232,-0.0000000001,-0.6795131167$ $\mathrm{H}, 0,-0.4529913557,-2.8447981923,-0.3253429232$ $\mathrm{H}, 0,-4.7992132346,-0.0000000006,-0.2020287542$ H,0,-1.7667344112,-0.0000000006,-4.468696546 $\mathrm{H}, 0,-0.4529913562,2.8447981922,-0.3253429225$

Species 9

Charge $=0$ Multiplicity $=1$

C, $0,0.006220515,-0.0112292987,0.0121197936$ C, $0,0.0145909097,-0.0256515165,1.5320015032$ H, $0,1.0370959966,-0.0139354624,1.9114477466$ H, $0,-0.5175799407,-0.898390246,1.9123512822$ C, $0,-0.7128195065,1.254496389,1.9099295044$ $\mathrm{O}, 0,0.6921585573,1.1505647389,-0.4603181023$ $\mathrm{O}, 0,-0.0064378933,2.3805647895,1.3842323278$ $\mathrm{O}, 0,-1.3024967974,2.2936918607,-0.5134531379$ $\mathrm{O}, 0,-1.3431878632,-0.0049289716,-0.460626109$ $\mathrm{O}, 0,-2.0417001359,1.2251145974,1.3838474966$ $\mathrm{N}, 0,-2.0417675114,1.1615601621,-0.0385595969$ $\mathrm{N}, 0,0.0484664069,2.3480255669,-0.0379018044$ $\mathrm{H}, 0,0.4882757519,-0.8604179171,-0.4672988323$ $\mathrm{H}, 0,-0.816313872,1.43653803,2.9774050658$

Species 10

Charge $=2$ Multiplicity $=1$ C, $0,1.4765072652,-0.0003529608,1.0720443757$ $\mathrm{H}, 0,1.4384137397,-0.0005485228,2.1615336502$ H,0,2.500669351,-0.0004036998,0.6985070387 C, $0,0.6282669413,1.100222305,0.4562738162$ C, $0,0.6283288465,-1.1007802742,0.4561004967$ C, $0,-0.6661970338,-1.335541726,1.0696439487$ H,0,-0.6748326809,-1.3060902985,2.1600309818 H,0,-1.1927514051,-2.2131534766,0.6963951381 
C, $0,-0.6660563955,1.3354714049,1.0699055373$ $\mathrm{H}, 0,-1.1923769867,2.2132571282,0.6967368976$ $\mathrm{H}, 0,-0.6747122405,1.30587985,2.1602861346$ C, $0,-1.4097608294,0.0000887505,0.5093932062$ $\mathrm{H}, 0,-2.3975224033,0.0001206478,0.9807653771$ C, $0,-1.3973240983,0.0001413008,-1.0145524876$ H, $0,-1.9274883707,-0.8763492788,-1.3995753271$ H, $0,-1.9276868206,0.8765222274,-1.3995430785$ C, $0,0.8109918825,1.3356764011,-0.9644054198$ $\mathrm{H}, 0,1.8451185435,1.3062284725,-1.3102310899$ H, $0,0.293121691,2.2134628003,-1.3492136028$ C, $0,0.8109494096,-1.3353341811,-0.9648096316$ $\mathrm{H}, 0,1.8450840805,-1.3057432205,-1.3106073536$ $\mathrm{H}, 0,0.2930994144,-2.212946052,-1.3500441068$ C, $0,0.0478911161,0.0002891489,-1.4982051105$ H,0,0.1902814617,0.0004824082,-2.5833730473

Species 11

Charge $=2$ Multiplicity $=1$ C, $0,0.3447731878,0.0000074159,0.2507152789$ $\mathrm{H}, 0,0.3218514842,-0.0001330782,1.3447378234$ H, $0,1.3783927876,0.000009471,-0.1083631378$ C, $0,-2.3067654706,-1.5839297168,0.2567203566$ $\mathrm{H}, 0,-2.3259308223,-1.5658288222,1.3507064848$ $\mathrm{H}, 0,-2.8496046694,-2.4682225079,-0.0916466791$ C, $0,-2.3066290072,1.5841537738,0.2571487904$ $\mathrm{H}, 0,-2.8493999139,2.468587138,-0.0909670432$ $\mathrm{H}, 0,-2.3257835701,1.5657497368,1.3511300943$ $\mathrm{C}, 0,-3.1488352368,0.0004958676,-2.2869202294$ $\mathrm{H}, 0,-3.6874136223,-0.8725427877,-2.6779683144$ $\mathrm{H}, 0,-3.6873195859,0.8737031709,-2.6777220442$ $\mathrm{C}, 0,-0.4701589809,1.5849455774,-2.2728959681$ $\mathrm{H}, 0,0.5637911063,1.5688714574,-2.6309655608$ $\mathrm{H}, 0,-0.971083174,2.4687801296,-2.6802502735$ C, $0,-0.47027353,-1.5841834515,-2.2733109589$ $\mathrm{H}, 0,0.5636850652,-1.5680590244,-2.6313552476$ H,0,-0.9712320964,-2.4678779442,-2.6809259224 $\mathrm{Si}, 0,-0.6482998375,1.4211553492,-0.4708796486$ Si, $0,-3.2642076594,0.0002416149,-0.4046872197$ H,0,-4.6110913225,0.0002200411,0.1990752994 Si, $0,-0.6484182396,-1.4208709632,-0.4712535331$ Si,0,-1.3945338505,0.0005067091,-2.9791610228 H, $0,-1.2368633267,0.0006839543,-4.4466937513$

Species 12

Charge $=2$ Multiplicity $=1$ C, $0,0.3773029533,-0.0000129297,0.2759258299$ H, $0,0.3436560113,-0.0001543492,1.3696248044$ H,0,1.4080378514,-0.0000088078,-0.0914340709
C, $0,-2.3864418553,-1.3484324514,0.1663814733$ $\mathrm{H}, 0,-2.4796521641,-1.3091558792,1.2531528907$ H, $0,-2.9772165318,-2.1898288381,-0.2020502893$ C, $0,-2.3863204022,1.3486816931,0.1667409598$ H,0,-2.9770225897,2.1902284771,-0.2014632039 $\mathrm{H}, 0,-2.4795291454,1.3091220767,1.2535024535$ C,0,-2.9246235762,0.0002369121,-0.5028032745 H, $0,-3.9851198662,0.0002480364,-0.2193154397$ C, $0,-2.8191843377,0.0004384431,-2.0471628321$ $\mathrm{H}, 0,-3.3532343831,-0.8723682009,-2.4337645467$ H, $0,-3.3531516509,0.8733997854,-2.4335295665$ C, $0,-0.5809415169,1.3478958281,-2.3217119941$ $\mathrm{H}, 0,0.4236037947,1.3086918557,-2.7469233353$ $\mathrm{H}, 0,-1.1131615673,2.190557253,-2.7683030029$ C, $0,-0.5810593054,-1.3471459546,-2.3220675808$ H, $0,0.4234893365,-1.3079170348,-2.7472688119$ H, $0,-1.1133533297,-2.1896415688,-2.7688833247$ C, $0,-1.3843050404,0.0004505507,-2.6285277389$ H, $0,-1.4442074168,0.0005981005,-3.7245171847$ Si,0,-0.6570165088,-1.3709464442,-0.4779669298 Si, $0,-0.6568963196,1.3712126514,-0.4776060265$

Species 13

Charge $=0$ Multiplicity $=1$

C, $0,0.0421487693,-0.0142324884,0.0051609631$ $\mathrm{H}, 0,0.065455425,-0.1227864846,1.0902391188$ $\mathrm{H}, 0,1.0708112968,0.0857557937,-0.343385662$ C, $0,-0.8640549651,1.111718338,-0.5518390886$ C, $0,-0.8044302707,-1.1259043629,-0.6632039038$ C, $0,-2.0907238333,-0.9204346652,0.1759599343$ $\mathrm{H}, 0,-1.8829234747,-0.9510827453,1.2462941178$ H, $0,-2.9132972087,-1.6077471912,-0.0255324955$ C, $0,-2.0081686637,1.847243927,0.0928225124$ H, $0,-2.4161696811,2.7101972114,-0.4278502202$ $\mathrm{H}, 0,-1.9819412809,1.987019417,1.1708730766$ C, $0,-2.3521193712,0.4795684686,-0.4326529304$ C,0,-2.6510068071,0.0086138696,-1.8780036523 H,0,-3.4247891974,-0.7598330849,-1.8998948738 $\mathrm{H}, 0,-2.930645126,0.7846508267,-2.5917776418$ C, $0,-0.5188934756,0.9164638382,-2.0493658572$ $\mathrm{H}, 0,0.5579751895,0.9366733756,-2.2214968767$ H, $0,-0.9825507572,1.6153672427,-2.7467265899$ C, $0,-0.6005101965,-1.8515449643,-1.9657632658$ H,0,0.4196736018,-2.0005798411,-2.3114148945 $\mathrm{H}, 0,-1.2396555933,-2.7052225241,-2.1777952216$ C,0,-1.1961196582,-0.4761418167,-2.0986395409 
Species 14

Charge $=0$ Multiplicity $=1$

C, $0,-0.3778964947,-0.0168070476,-0.2477657395$

$\mathrm{H}, 0,-0.3880021051,-0.0341933652,0.8429021434$ $\mathrm{H}, 0,0.6617664439,0.0007173593,-0.582696739$ C, $0,-3.0864972558,-1.4909759381,-0.305674471$ $\mathrm{H}, 0,-3.0785077738,-1.450372493,0.7840294972$ $\mathrm{H}, 0,-3.6091671236,-2.3839461132,-0.6483063916$ C, $0,-3.117331226,1.5951403001,-0.2810616087$ $\mathrm{H}, 0,-3.6005601532,2.5059763128,-0.6413547762$ $\mathrm{H}, 0,-3.1482046818,1.5911119353,0.8087767164$ C,0,-4.0152430293,-0.0212513071,-2.8662347991 $\mathrm{H}, 0,-4.5388366044,-0.9219161276,-3.1915281825$ $\mathrm{H}, 0,-4.534397739,0.8468920288,-3.278864631$ C, $0,-1.333827753,1.4204837895,-2.7614454327$ H,0,-0.2959293679,1.448478972,-3.1361484096 H, $0,-1.7715423371,2.3432636444,-3.1784273269$ C, $0,-1.3011684082,-1.6282722388,-2.8287732597$ $\mathrm{H}, 0,-0.2866544131,-1.6835756056,-3.2296059275$ H, $0,-1.844779847,-2.5188262214,-3.1508867742$ Si, $0,-3.7802250824,0.0855592549,-1.0639166678$ Si,0,-1.3435125452,-1.3628731454,-1.0240792471 Si, $0,-1.1954620563,1.7100764425,-0.8655763125$ $\mathrm{Si}, 0,-2.1786815743,-0.03469047,-3.7184778558$

Species 15

Charge $=0$ Multiplicity $=1$

C, $0,-0.2926793558,-0.0350223746,-0.1964615944$ $\mathrm{H}, 0,-0.3124840212,0.0068648134,0.8949729534$ $\mathrm{H}, 0,0.7489680025,0.0233614066,-0.5211773775$ C, $0,-2.625652422,-1.3839426114,-0.296338409$ $\mathrm{H}, 0,-2.6515487843,-1.4193755755,0.7949413958$ $\mathrm{H}, 0,-3.1553870798,-2.2267499566,-0.7458720864$ C, $0,-2.415198387,1.302295718,-0.2034210016$ $\mathrm{H}, 0,-2.8107631487,2.266490034,-0.5317205428$ $\mathrm{H}, 0,-2.3744782386,1.3042717336,0.8882454662$ C, $0,-3.1532094649,0.1119412152,-2.4802901819$ $\mathrm{H}, 0,-3.6380634068,-0.72483402,-2.9885575956$ $\mathrm{H}, 0,-3.5762124877,1.0391851495,-2.8748870972$ C, $0,-0.9845750259,1.2098367845,-2.1956638286$ $\mathrm{H}, 0,0.0572056754,1.1980239209,-2.5250063852$ $\mathrm{H}, 0,-1.4440680452,2.1431600361,-2.529805456$ C,0,-1.0359352594,-1.2212064723,-2.4728903655 H, $0,-0.0144276683,-1.2020873325,-2.8608900329$ $\mathrm{H}, 0,-1.577487755,-2.0216947585,-2.9821831748$ B, $0,-3.0288210873,0.0198372649,-0.902348987$ B, $0,-1.1818785311,-1.1444681974,-0.8956367111$ N, $0,-1.6850568511,0.0935939925,-2.8515575328$ $\mathrm{N}, 0,-0.9977851589,1.1962715013,-0.7232330134$
Species 16

Charge $=2$ Multiplicity $=1$

C, $0,0.0532371438,0.0000288549,0.0380406627$ $\mathrm{H}, 0,0.019665738,-0.0001176823,1.1261663249$ H,0,1.0770444598,0.0000345803,-0.3319842953 C, $0,-0.8236750735,1.0502730405,-0.5980744474$ C, $0,-0.8237685934,-1.049965951,-0.5983595516$ C, $0,-2.1838837556,-1.2906758733,0.0096244553$ H, $0,-2.1877442417,-1.2731267941,1.0980517762$ H,0,-2.6876797234,-2.1741009872,-0.3788465071 C,0,-2.1837703437, 1.2909412141,0.0099722878 H, $0,-2.6874852728,2.1745155765,-0.3782642079$ $\mathrm{H}, 0,-2.1876336875,1.2731006171,1.0983949911$ C, $0,-2.6436825079,0.0002384109,-0.6215862772$ C, $0,-2.9036272163,0.0004483554,-2.1077895917$ $\mathrm{H}, 0,-3.3982638307,-0.9001030724,-2.467511509$ $\mathrm{H}, 0,-3.3981855833,0.9011385459,-2.4672716323$ C, $0,-0.6665722904,1.2914068409,-2.0790495286$ $\mathrm{H}, 0,0.3674925865,1.2734770651,-2.4188211223$ H,0,-1.1918970593,2.174737921,-2.4380121502 C,0,-0.6666864497,-1.2907142911,-2.0794003324 $\mathrm{H}, 0,0.3673799269,-1.2727858372,-2.4191673702$ H,0,-1.192091044,-2.1739016981,-2.4385993257 C,0,-1.4091652097,0.0004111607,-2.320907649

Species 16 triplet

Charge $=2$ Multiplicity $=3$

C, $0,-0.011806405,-0.0001417383,-0.0087496061$ $\mathrm{H}, 0,-0.0274627186,0.0985818692,1.0786626299$ $\mathrm{H}, 0,1.0172441828,-0.0985582546,-0.3601695611$ C, $0,-0.7708469345,1.1404881378,-0.6762383537$ C, $0,-0.8822392086,-1.1404577487,-0.5239178784$ C,0,-2.2394486057,-1.3862467089,0.0872763638 $\mathrm{H}, 0,-2.240334542,-1.3631560337,1.1777145694$ $\mathrm{H}, 0,-2.7442911664,-2.2696851698,-0.3057245528$ C, $0,-2.1503060173,1.2347908558,-0.035554074$ $\mathrm{H}, 0,-2.7433012912,2.0730005783,-0.4071160132$ $\mathrm{H}, 0,-2.0777633107,1.2814242493,1.0529589698$ C, $0,-2.6941297869,-0.0940873668,-0.547001537$ C, $0,-2.837996713,0.0004552915,-2.0610235873$ $\mathrm{H}, 0,-3.2868679512,-0.8884469041,-2.5091232097$ H, $,-3.4030501495,0.8893015453,-2.3492951973$ C, $0,-0.6101064737,1.3872697355,-2.1558156728$ H,0,0.4264650058, 1.3656917573,-2.4944967693 H, $0,-1.1417055809,2.2700438071,-2.5133112265$ C, $0,-0.6998712523,-1.2346410978,-2.0340607403$ $\mathrm{H}, 0,0.3576632647,-1.2828525312,-2.3018815312$ $\mathrm{H}, 0,-1.2375776466,-2.0723126353,-2.4827463424$ C, $0,-1.3532587268,0.0947983587,-2.3937816798$ 
Species 17

Charge $=2$ Multiplicity $=1$

C, $0,0.3782779497,-0.0000038695,0.2761524457$ $\mathrm{H}, 0,0.3651883656,-0.000150492,1.3689072705$ $\mathrm{H}, 0,1.4156146984,-0.0000010158,-0.0671249642$ C, $0,-2.3500013557,-1.5760140625,0.2390937091$ H, $0,-2.3659979968,-1.5821685085,1.3317233287$ H, $0,-2.8617567485,-2.4691372847,-0.1280371846$ C, $0,-2.3498657954,1.5762415005,0.2395373619$ $\mathrm{H}, 0,-2.8615508986,2.4695164216,-0.1273218216$ $\mathrm{H}, 0,-2.3658480546,1.5820736529,1.332169104$ C, $0,-3.2292751558,0.0005036096,-2.3413087141$ $\mathrm{H}, 0,-3.7433092827,-0.888411688,-2.7153750293$ $\mathrm{H}, 0,-3.7432205673,0.8895705826,-2.7151367175$ C, $0,-0.4990035968,1.5756027555,-2.3101229554$ $\mathrm{H}, 0,0.5347404247,1.5793234736,-2.6645799361$ $\mathrm{H}, 0,-1.0048147837,2.4698406254,-2.6824366472$ C, $0,-0.4991007172,-1.5748179352,-2.3105511441$ $\mathrm{H}, 0,0.5346587229,-1.5784548946,-2.6649668138$ H,0,-1.0049137485,-2.4689357049,-2.6831480194 Si, $,-0.5997407348,1.4405716783,-0.437333786$ Si, $0,-3.0968138128,0.0002459123,-0.4658861062$ Si, $0,-0.5998637815,-1.4403001318,-0.4377287138$ Si,0,-1.4044078941,0.0004856723,-2.7997199131

Species 18

Charge $=2$ Multiplicity $=1$

C, $0,0.4066037246,-0.0000148132,0.2956636452$ H,0,0.3950393034,-0.0001623224,1.3895296159 $\mathrm{H}, 0,1.4442755814,-0.0000136737,-0.0502722391$ C, $0,-2.4501274294,-1.277018396,0.1259647339$ $\mathrm{H}, 0,-2.5183937145,-1.2500384726,1.2136145209$ H,0,-3.0063273793,-2.1166143098,-0.2920858046 C, $0,-2.4500159675,1.2772800648,0.1263067508$ $\mathrm{H}, 0,-3.0061436262,2.1170367507,-0.2915168579$ $\mathrm{H}, 0,-2.5182826341,1.2500126786,1.2139493583$ C, $0,-2.6784856954,0.0002301799,-0.5435857137$ C, $0,-2.8317254384,0.0004377687,-2.0556739356$ H, $0,-3.3375033068,-0.8917967646,-2.4230734759$ $\mathrm{H}, 0,-3.3374230035,0.8928159587,-2.4228351399$ C, $0,-0.6385595815,1.2775837315,-2.3692220379$ $\mathrm{H}, 0,0.3742754109,1.2509384458,-2.7716682323$ H, $0,-1.2085247631,2.1175023704,-2.7675983439$ C, $0,-0.6386697166,-1.2768157424,-2.3695643068$ H, $0,0.3741677925,-1.2501512548,-2.7720028444$ H, $0,-1.2087076867,-2.1165787323,-2.7681645916$ C, $0,-1.3458649444,0.0004154447,-2.3790403543$ Si,0,-0.5853728187,-1.4237350618,-0.426251428 Si, $0,-0.5852481212,1.4239842205,-0.4258686138$
Species 19

Charge $=2$ Multiplicity $=1$

C, $0,0.2422301853,-0.0000005684,0.1761665819$ $\mathrm{H}, 0,0.1877181839,-0.0001349975,1.2595761557$ $\mathrm{H}, 0,1.2565673149,0.0000084396,-0.2083461064$ C, $0,-0.7941348007,0.7900856845,-0.5771760635$ C, $0,-0.7941988299,-0.7898066208,-0.5773777649$ C, $0,-2.1505919062,-1.1786085199,-0.02263621$ H,0,-2.2501055091,-1.1457178734,1.0615269959 H,0,-2.543821709,-2.1250732641,-0.3915424973 C, $0,-2.1504813562,1.1788855141,-0.0223251721$ $\mathrm{H}, 0,-2.5436195489,2.1254864125,-0.3909803354$ $\mathrm{H}, 0,-2.2499924313,1.1457157514,1.0618296328$ C, $0,-2.9215328029,0.0004512233,-2.1206499942$ $\mathrm{H}, 0,-3.4252932667,-0.8941571685,-2.4865624766$ H, $0,-3.4252121528,0.8952008104,-2.4863288645$ C, $0,-0.6870170068,1.1790035041,-2.038394133$ H, $0,0.3130337778,1.1454696016,-2.4687913245$ $\mathrm{H}, 0,-1.1590941036,2.1258217045,-2.2974606365$ C, $0,-0.6871229998,-1.1783281268,-2.0387060966$ H, $0,0.312929659,-1.1447691187,-2.469096998$ H,0,-1.1592843809,-2.1250344767,-2.2980274665 $\mathrm{N}, 0,-2.9678392572,0.0002534894,-0.5973264281$ N,0,-1.4873490663,0.0004535959,-2.6374093093 $\mathrm{H}, 0,-3.9567269093,0.0002634826,-0.3105708003$ $\mathrm{H}, 0,-1.5212379916,0.0005921575,-3.666471579$

Species 20

Charge $=2$ Multiplicity $=1$

C, $0,0.0069151753,0.0000000018,0.0055121619$ $\mathrm{H}, 0,0.0175435117,0.000000001,1.1013918349$ $\mathrm{H}, 0,1.0541998196,0.0000000023,-0.3169511709$ C, $0,-2.7617280837,-1.2789575652,-0.2147587068$ $\mathrm{H}, 0,-2.9481428574,-1.1899149353,0.8567991677$ H, $0,-3.3674513039,-2.1111728311,-0.5829141796$ C, $0,-2.7617280843,1.2789575685,-0.2147587055$ $\mathrm{H}, 0,-3.3674513043,2.1111728348,-0.5829141781$ $\mathrm{H}, 0,-2.9481428584,1.189914938,0.8567991688$ C, $0,-3.2445365581,0.0000000024,-2.3597144975$ H, $0,-3.7499776383,-0.8932630631,-2.727520726$ H, $0,-3.749977638,0.8932630685,-2.7275207246$ C, $0,-1.0539163969,1.2787740371,-2.562409878$ H,0,-0.0915129391,1.1885820551,-3.0690708664 H,0,-1.5894916192,2.1114591454,-3.0257422867 C, $0,-1.0539163964,-1.2787740305,-2.5624098797$ H,0,-0.0915129385,-1.188582047,-3.0690708676 H,0,-1.589491618,-2.1114591384,-3.0257422899 $\mathrm{N}, 0,-3.3242317528,0.0000000019,-0.855576198$ $\mathrm{N}, 0,-1.8372604725,0.0000000034,-2.90003919$ 
H,0,-4.3328261513,0.0000000017,-0.6631301343 H,0,-1.9652945852,0.0000000042,-3.9187722402 Si, $0,-0.9011601519,-1.5000467781,-0.6570356993$ H,0,-0.4398567095,-2.8565107976,-0.3210485538 Si, $0,-0.9011601524,1.5000467822,-0.6570356974$ $\mathrm{H}, 0,-0.4398567103,2.8565108015,-0.32104855$

Species 21

Charge $=2$ Multiplicity $=1$ C, $0,1.3777603827,-0.0001780658,1.1661523206$ $\mathrm{H}, 0,1.302906398,-0.0048190181,2.2538238734$ $\mathrm{H}, 0,2.4171657275,0.0045457897,0.84066106$ C, $0,-0.76221375,-1.4077928532,1.0463246383$ $\mathrm{H}, 0,-0.8439801498,-1.3705016037,2.135429363$ $\mathrm{H}, 0,-1.2413523168,-2.2871706732,0.6191866645$ C,0,-0.7713988068,1.3940121807,1.057902138 $\mathrm{H}, 0,-1.2567282534,2.2735838206,0.6381922647$ $\mathrm{H}, 0,-0.8527321631,1.3471454194,2.1466626393$ C, $0,-1.4168684136,0.0002015205,-1.2084032219$ $\mathrm{H}, 0,-1.8277180941,-0.9001380579,-1.6617167765$ $\mathrm{H}, 0,-1.833710858,0.9014629037,-1.654351581$ C,0,0.7599840062,1.2660686647,-0.9574731689 $\mathrm{H}, 0,1.7967173908,1.2160378309,-1.284081606$ $\mathrm{H}, 0,0.2490951173,2.1221012866,-1.3943581214$ C, $0,0.7685517557,-1.2530494189,-0.9675815149$ H,0,1.8049703918,-1.1929241996,-1.2935103115 H,0,0.2639884793,-2.1090215492,-1.4118890281 B, $0,-1.3092347337,-0.0060214945,0.4001732904$ $\mathrm{N}, 0,0.0406226232,0.0054356987,-1.3003221041$ C, $0,0.5420754132,1.0979332767,0.533278143$ C,0,0.549308352,-1.098569366,0.5243573052

Species 22

Charge $=2$ Multiplicity $=1$ C, $0,0.0667140278,-0.1533810693,-0.0142931676$ C, $0,-0.1321167465,-0.0529087018,1.985136643$ C, $0,1.3325125794,0.0410520951,2.3757294364$ H,0,1.824968706,-0.9350178246,2.4314894811 $\mathrm{H}, 0,1.5066204937,0.700679081,3.2318137833$ C, $0,1.5343078649,0.7335797542,1.0390932709$ C, $0,-0.2732585892,1.5954793869,0.8395604618$ $\mathrm{O}, 0,-0.4633984549,-0.9362763169,0.964193501$ $\mathrm{O}, 0,1.4210097501,-0.0455092641,-0.1055185393$ $\mathrm{O}, 0,-0.6484246516,0.9789155365,-0.3329342508$ O,0,-0.8656430002,1.126494942,1.9726059393 $\mathrm{O}, 0,1.0188765566,2.0174539326,0.9028462235$
Species 23

Charge $=2$ Multiplicity $=1$

C, $0,0.126607065,-0.0000156583,0.0920042963$ $\mathrm{H}, 0,0.0996187347,-0.0113885155,1.1880609004$ H,0,1.1648466141,0.0113390447,-0.2598853842 O,0,-2.4650424703,1.3241228917,-0.1300657676 O,0,-2.4450794264,-1.3591958867,-0.1571994747 O,0,-3.208812926,0.0000602266,-2.3368196325 $\mathrm{O}, 0,-0.8981032677,1.3584829995,-2.283761436$ O, $0,-0.8783146546,-1.3231204559,-2.3109013111$ Si, $0,-0.8628757889,-1.4451451394,-0.6549456543$ Si, $0,-0.8850005331,1.4448909726,-0.6249854678$ Si,0,-1.6550763306,0.0192428356,-2.9442456976 Si,0,-3.309459994,-0.0192732845,-0.6706189794

Species 24

Charge $=2$ Multiplicity $=1$ C, $0,-0.0426783197,0.1094778764,0.06311146$ C, $0,0.0139905988,-0.032563268,1.5678278695$ $\mathrm{H}, 0,0.9971840679,0.0269646741,2.0340597546$ H, $0,-0.7025601106,-0.7119052897,2.0288804496$ C, $0,-0.5367199924,1.2378008168,0.9594845257$ $\mathrm{O}, 0,0.9531286269,0.7124773665,-0.7481120009$ $\mathrm{O}, 0,0.2302215943,2.3650836647,0.563822759$ $\mathrm{O}, 0,-0.8696880363,2.0223441839,-1.5054578715$ $\mathrm{O}, 0,-1.1588997232,-0.205353357,-0.7559391752$ O,0,-1.8812298558,1.4462846482,0.5576264361 $\mathrm{N}, 0,-1.7509871404,1.0660159932,-0.7885166383$ $\mathrm{N}, 0,0.4265780543,2.0143119734,-0.7801569273$ $\mathrm{H}, 0,1.038822467,2.6919352172,-1.296139588$ H,0,-2.6615238834,1.081499632,-1.3090283436

Species 25

Charge $=1$ Multiplicity $=1$ C,0,0.0060621513,-0.0499433977,0.0044366137 $\mathrm{H}, 0,-0.0011833628,0.0515271476,1.0908328413$ $\mathrm{H}, 0,1.0367703484,0.0522331281,-0.3387649184$ C, $0,-0.8935190824,0.983778798,-0.6485995125$ C, $0,-0.6265436516,-1.3943719721,-0.4557201234$ C,0,-2.1165146922,-1.2751571174,-0.0224796501 H, $0,-2.2217112214,-1.2297324835,1.0625958905$ $\mathrm{H}, 0,-2.7129579027,-2.1131324298,-0.3865583751$ C, $0,-2.2032556551,1.3253916524,-0.005725577$ $\mathrm{H}, 0,-2.7102475794,2.2132477751,-0.374732347$ $\mathrm{H}, 0,-2.1892318369,1.2762833706,1.0782064614$ C, $0,-2.5495400671,0.0275742208,-0.669815923$ C, $0,-2.9216601604,0.035986009,-2.1210370087$ H,0,-3.3912336668,-0.8810706988,-2.4617169607 
H, $0,-3.4292744179,0.9236951875,-2.4895348446$ C, $0,-0.6875294149,1.3254026392,-2.0928789276$ $\mathrm{H}, 0,0.3477413523,1.2762033262,-2.414347516$ $\mathrm{H}, 0,-1.195409274,2.2131333084,-2.4608646805$ C, $0,-0.676365938,-1.2748583945,-2.0059047565$ H, $0,0.3228342048,-1.2294163336,-2.4419159745$ H, $0,-1.207210483,-2.1130380975,-2.4599637623$ C,0,-1.4263034478,0.0275209623,-2.2176331211 H,0,-0.1166362697,-2.2862820693,-0.0853994958

Species 26

Charge $=1$ Multiplicity $=1$ C, $0,0.3207531931,-0.0220275158,0.2349531227$ $\mathrm{H}, 0,0.328853021,0.0195128483,1.32966769$ $\mathrm{H}, 0,1.3670415705,0.0211724447,-0.08651691$ C,0,-2.3005196362,-1.5385721189,0.1995878996 $\mathrm{H}, 0,-2.3645633348,-1.54119824,1.2931454894$ H, $0,-2.8535378199,-2.4180684491,-0.1479134607$ C, $0,-2.3710513993,1.6122424085,0.2209874878$ $\mathrm{H}, 0,-2.8822238033,2.5048833104,-0.1390254993$ H,0,-2.3819302656,1.6081236957,1.3121386397 C, $0,-3.2493812594,0.039711026,-2.3555299124$ $\mathrm{H}, 0,-3.7544417895,-0.8549039648,-2.7235572798$ $\mathrm{H}, 0,-3.7660143828,0.9229475982,-2.7303925562$ C, $0,-0.5223217186,1.6114454529,-2.3238151624$ $\mathrm{H}, 0,0.5119999612,1.6027486412,-2.6718752106$ $\mathrm{H}, 0,-1.0190104561,2.5058412445,-2.6989544118$ C, $0,-0.5226309122,-1.5366462858,-2.2525656127$ $\mathrm{H}, 0,0.4967785967,-1.5385273654,-2.6535588295$ H,0,-1.0238824048,-2.4170160031,-2.6693249719 Si, $0,-3.0976556646,0.0185199347,-0.4772736632$ Si,0,-1.4158951943,0.0201054664,-2.798283186 Si,0,-0.4789786122,-1.6494237204,-0.3510054359 $\mathrm{H}, 0,0.217095132,-2.8656847992,0.1545644765$ Si, $0,-0.6145398738,1.4535039211,-0.4471471481$

Species 27

Charge $=1$ Multiplicity $=1$

C, $0,0.3423499755,-0.0334119266,0.2496116264$ $\mathrm{H}, 0,0.3533242938,0.0089645141,1.3446550691$ H, $0,1.3893250303,0.0092661631,-0.0710643337$ C,0,-2.3461106776,-1.2467698301,0.11448213 $\mathrm{H}, 0,-2.4393588982,-1.184842193,1.2003160724$ H, $0,-2.9848619392,-2.055328408,-0.251933064$ C, $0,-2.5097006549,1.3030902546,0.0989794231$ $\mathrm{H}, 0,-3.0386468219,2.148960501,-0.3335546356$ $\mathrm{H}, 0,-2.552602127,1.2921453591,1.1861050005$ C, $0,-2.8306218689,0.0195462834,-2.0545507986$ H,0,-3.3149619524,-0.8906090491,-2.4061710821
H, $0,-3.3540393884,0.8964280149,-2.4341685539$ C, $0,-0.6832468345,1.3031953949,-2.4188871826$ $\mathrm{H}, 0,0.3365962594,1.2924010481,-2.7979579554$ H, $0,-1.2586856571,2.1495429467,-2.7861639135$ C, $0,-0.6178828441,-1.2464102187,-2.2670320685$ $\mathrm{H}, 0,0.3856683343,-1.1842477226,-2.6922470297$ $\mathrm{H}, 0,-1.1637538494,-2.05514051,-2.7610165185$ Si, $0,-0.5143448663,-1.5959771658,-0.3751326623$ H,0,0.0084651369,-2.9347868427,0.0040606476 $\mathrm{Si}, 0,-0.5736336935,1.4853666282,-0.418185479$ C, $0,-1.3482552378,0.0389002411,-2.3606597349$ C, $0,-2.6610787761,0.0384060479,-0.5511793944$

Species 28

Charge $=0$ Multiplicity $=1$ C, $0,-0.0077113029,0.0525352374,-0.0480516597$ $\mathrm{H}, 0,-0.0145929572,-0.1539866623,1.0252282309$ $\mathrm{H}, 0,1.0359734406,0.0521789231,-0.3790126323$ C, $0,-0.7127476269,1.3775144793,-0.4366579528$ $\mathrm{H}, 0,-0.2273544133,2.2818153339,-0.0501301024$ C, $0,-0.8943559334,-0.9229590501,-0.8248729571$ C, $0,-2.196785802,-1.2112236949,-0.0754747626$ H,0,-2.0351743083,-1.3189337646,1.0001103821 H,0,-2.711092061,-2.1116966777,-0.4263139212 C, $0,-2.2034327676,1.3244598047,0.0375800469$ $\mathrm{H}, 0,-2.720217122,2.2277265257,-0.3064051767$ $\mathrm{H}, 0,-2.2312029954,1.3475861108,1.1330350383$ C, $0,-2.9849088653,0.065528738,-0.4658943444$ $\mathrm{H}, 0,-4.0179516616,0.092983152,-0.0986680804$ C, $0,-2.8525706015,-0.033457588,-2.0071677543$ $\mathrm{H}, 0,-3.3784483873,-0.9141660804,-2.3900723953$ $\mathrm{H}, 0,-3.2362104374,0.8396861049,-2.5411183977$ C, $0,-0.6640211468,1.2301906728,-1.9792507857$ $\mathrm{H}, 0,0.3688780589,1.2489666285,-2.3418466948$ H, $0,-1.2182262318,2.0047922771,-2.5152856007$ C, $0,-0.577831855,-1.442319432,-2.2018536344$ H, $0,0.4571792692,-1.4092722978,-2.5332084503$ H, $0,-1.1193506035,-2.3178132185,-2.5519514953$ C,0,-1.3295328791,-0.1415977946,-2.1049867758

Species 29

Charge $=0$ Multiplicity $=1$

C, $0,0.0662530246,-0.1055426153,0.1044185463$ H,0,-0.0011412372,-0.0536943287,1.1898745492 H, $0,1.087089161,-0.3176842657,-0.21204353$ C, $0,-0.9427941659,-1.0340564433,-0.4874681424$ C, $0,-2.3120369894,-1.1490713227,0.0983865612$ $\mathrm{H}, 0,-2.3091659272,-1.0670394062,1.1840766667$ H, $0,-2.8455723582,-2.0433135041,-0.2225937785$ 
C, $0,-2.0863718458,1.5714978408,-0.1068966869$ $\mathrm{H}, 0,-2.4792570749,2.4680921559,-0.5859824442$ $\mathrm{H}, 0,-2.1316476835,1.6687487263,0.9776950489$ C, $0,-2.8371433471,0.0613937223,-2.2621444464$ $\mathrm{H}, 0,-3.3774203483,-0.8181212389,-2.6111582323$ $\mathrm{H}, 0,-3.1880936759,0.9593482065,-2.7679983255$ C, $0,-0.4588762747,1.1047590767,-2.2570140389$ H, $0,0.5552494317,0.9079827161,-2.6035701527$ $\mathrm{H}, 0,-0.8807539153,1.9721198972,-2.7622739357$ C, $0,-0.7701907566,-1.419176345,-1.9317716535$ $\mathrm{H}, 0,0.2689602339,-1.552838968,-2.2313343034$ $\mathrm{H}, 0,-1.3744945162,-2.2734721091,-2.2354962398$ C, $0,-1.3526607348,-0.0896884242,-2.32932039$ B, $0,-2.6691752268,0.2142286996,-0.6720927799$ B, $0,-0.6908706731,1.0824884032,-0.6678227655$

Species 30

Charge $=0$ Multiplicity $=1$

C, $0,0.0190448765,-0.0287820214,-0.0104922329$ $\mathrm{H}, 0,-0.0039207849,0.0015394757,1.0807728255$ $\mathrm{H}, 0,1.0448351678,-0.1632501986,-0.3565716025$ C,0,-2.8799241249,-1.1512771764,-0.0681428146 $\mathrm{H}, 0,-2.9190908837,-1.1247158668,1.0227468178$ $\mathrm{H}, 0,-3.5358778973,-1.9377236725,-0.4440710907$ C,0,-2.2399451341,1.4987159909,-0.1319659595 $\mathrm{H}, 0,-2.6034240565,2.4570383489,-0.5107065297$ $\mathrm{H}, 0,-2.2636707085,1.4972543498,0.960386596$ C, $0,-3.4008652976,0.3002058445,-2.2911461141$ $\mathrm{H}, 0,-4.0458133533,-0.5048728069,-2.6461313473$ H, $0,-3.7835351016,1.2628134126,-2.6363216164$ $\mathrm{C}, 0,-0.5003934643,1.4277889584,-2.2306242635$ $\mathrm{H}, 0,0.5305953612,1.2763567027,-2.5537902112$ H, $0,-0.8577677743,2.4004384994,-2.5747369119$ C, $0,-0.9697278814,-1.6497567367,-2.492926426$ H, $0,0.0525676066,-1.8088840107,-2.83640386$ $\mathrm{H}, 0,-1.6042249867,-2.4520806148,-2.869938$ B, $0,-2.9875855783,0.2524299153,-0.772533703$ B, $0,-0.8244916226,1.0917139384,-0.7262135562$ Si,0,-1.0693918344,-1.4924842607,-0.5997747577 $\mathrm{Si}, 0,-1.6269478715,0.0680992652,-2.9763202346$

Species 31

Charge $=0$ Multiplicity $=1$ C, $0,-0.1539752434,0.0001600263,-0.1059135719$ H, $0,-0.1945935366,-0.005339616,0.9840938345$ $\mathrm{H}, 0,0.8795794666,0.005573737,-0.4589929305$ C, $0,-2.5123598503,-1.2743502473,-0.2291147246$ $\mathrm{H}, 0,-2.6314571301,-1.2145888496,0.853555377$ H,0,-3.1120753632,-2.0994493353,-0.6157918894
C, $0,-2.5215154526,1.2584247368,-0.2162765798$ $\mathrm{H}, 0,-3.1272252633,2.0830394743,-0.5945866262$ $\mathrm{H}, 0,-2.6401680981,1.1868427043,0.8657278279$ C, $0,-3.2057968502,0.0001220382,-2.3052702825$ H, $0,-3.7696905619,-0.8910785199,-2.5841966614$ H,0,-3.7762887229,0.8898795916,-2.5752070199 C, $0,-0.9041712257,1.3797052571,-2.3540312535$ H,0,0.1349012061,1.3737330737,-2.6905388307 H,0,-1.4279604349,2.2654640414,-2.7155491257 C, $0,-0.8940157499,-1.3617804044,-2.3679718222$ $\mathrm{H}, 0,0.1451552394,-1.3448105174,-2.7038557439$ $\mathrm{H}, 0,-1.4109355602,-2.2479136091,-2.7383366589$ N, $0,-3.0231945599,-0.0067158935,-0.8255172793$ $\mathrm{B}, 0,-1.6436339358,0.0074806996,-2.6382021789$ B,0,-1.040977762,1.1157944604,-0.7982319631 B, $0,-1.0330024127,-1.1148372362,-0.8093130945$

Species 32

Charge $=1$ Multiplicity $=1$ C, $0,0.0100774119,-0.0000000011,0.0069447267$ $\mathrm{H}, 0,0.0002055283,-0.0000000011,1.1003366667$ $\mathrm{H}, 0,1.0624828612,-0.0000000027,-0.2929161119$ C,0,-0.6778538122, $1.2550921846,-0.5445257614$ $\mathrm{H}, 0,-0.2458800486,2.1686034617,-0.1314216926$ C, $0,-0.6778538177,-1.2550921844,-0.5445257612$ $\mathrm{H}, 0,-0.2458800544,-2.1686034618,-0.131421693$ C, $0,-2.2269897428,-1.2463673839,-0.0399524628$ $\mathrm{H}, 0,-2.2385608093,-1.2333706043,1.0488774826$ $\mathrm{H}, 0,-2.724876179,-2.1330802268,-0.4295598822$ C, $0,-2.2269897382,1.246367385,-0.0399524631$ $\mathrm{H}, 0,-2.7248761747,2.1330802281,-0.4295598814$ $\mathrm{H}, 0,-2.2385608045,1.2333706049,1.0488774823$ C,0,-2.6560312219,0.0000000007,-0.6566596659 C, $0,-2.9026546336,-0.0000000013,-2.0906863616$ $\mathrm{H}, 0,-3.3940538563,-0.898762383,-2.4603946608$ $\mathrm{H}, 0,-3.3940538604,0.8987623774,-2.4603946621$ C, $0,-0.6765573307,1.2674830853,-2.0782653584$ $\mathrm{H}, 0,0.3551573237,1.3051287666,-2.4410964369$ $\mathrm{H}, 0,-1.1719594792,2.1643790112,-2.4598179057$ C, $0,-0.6765573286,-1.2674830833,-2.0782653582$ H, $0,0.355157328,-1.3051287598,-2.4410964317$ $\mathrm{H}, 0,-1.1719594714,-2.1643790108,-2.4598179082$ C,0,-1.3586950886,0.0000000003,-2.6088093102 H,0,-1.4207298302,0.0000000008,-3.6987380535

Species 33

Charge $=2$ Multiplicity $=1$ C, $0,0.0291780879,-0.0599255781,0.0204731065$ H,0,0.0165204572,-0.065059312,1.1104666167 
H, $0,1.0525047257,-0.0652211105,-0.3550200494$ C,0,-0.7201102321,1.2583465242,-0.509850067 $\mathrm{H}, 0,-0.1556380083,2.1039509428,-0.1105786528$ C, $0,-0.835858974,-1.0668801382,-0.5911985086$ C, $0,-2.1407240855,-1.3123214616,0.0202109714$ $\mathrm{H}, 0,-2.1297011897,-1.304289951,1.110117731$ H, $0,-2.6472917563,-2.201261309,-0.3558561602$ C, $0,-2.1801836914,1.2618086469,0.0045916687$ $\mathrm{H}, 0,-2.218517682,1.3280474327,1.0941839857$ C, $0,-2.9079735631,-0.0038184264,-0.5093129677$ $\mathrm{H}, 0,-3.922385331,-0.0700552655,-0.1099967427$ C, $0,-2.909704578,-0.0009417896,-2.0568165999$ $\mathrm{H}, 0,-3.4741768016,-0.8465462082,-2.4560880141$ C, $0,-0.721841247,1.261223161,-2.0573536992$ $\mathrm{H}, 0,0.2925705209,1.3274600004,-2.4566699243$ C, $0,-0.6938671984,-1.3127767334,-2.0248900696$ $\mathrm{H}, 0,0.3375230729,-1.3037925355,-2.3775411503$ $\mathrm{H}, 0,-1.2169471032,-2.2016398334,-2.3776539908$ C, $0,-1.4496311187,-0.0044039123,-2.5712583355$ $\mathrm{H}, 0,-1.4112971281,-0.0706426982,-3.6608506525$ C, $0,-1.4890907245,2.5697261965,-2.5868776377$ $\mathrm{H}, 0,-0.9825230539,3.4586660437,-2.2108105051$ H, $0,-1.5001136204,2.5616946868,-3.6767843972$ C, $0,-2.9359476122,2.5701814678,-0.541776597$ $\mathrm{H}, 0,-3.9673378835,2.5611972687,-0.1891255166$ $\mathrm{H}, 0,-2.4128677081,3.4590445681,-0.1890126751$ C,0,-3.6589928976,1.3173303127,-2.5871397734 $\mathrm{H}, 0,-4.6823195356,1.3226258452,-2.2116466183$ $\mathrm{H}, 0,-3.6463352658,1.3224640467,-3.6771332837$ C, $0,-2.7939558361,2.3242848728,-1.9754681579$

Species 34

Charge $=2$ Multiplicity $=1$

C, $0,-0.0019145871,0.003721575,0.0279424178$

$\mathrm{H}, 0,0.0384150157,-0.017882517,1.1233086836$

$\mathrm{H}, 0,1.0369886494,0.027471721,-0.3093768015$

C, $0,-0.7209980584,1.2628367676,-0.4587822594$

H, $0,-0.2340269317,2.1883993079,-0.1498771409$

C, $0,-0.7371146649,-1.2379800528,-0.4570390737$

C, $0,-2.180549358,-1.2536902068,0.0283220846$

$\mathrm{H}, 0,-2.1811879017,-1.2980015756,1.1237302292$

H, $0,-2.7201815047,-2.1419279815,-0.3081595738$

C, $0,-2.1969399783,1.2894085762,-0.2371482243$

C, $0,-2.9121481325,-0.0013906365,-0.459139353$

$\mathrm{H}, 0,-3.9573525319,0.0399445048,-0.1508312211$

C, $0,-2.9088167511,-0.0054320328,-2.1078844081$

H, $0,-3.3957878778,-0.9309945731,-2.4167895266$

C,0,-0.717666677,1.2587953712,-2.1075273144

H, $0,0.3275377224,1.21746023,-2.4158354466$

C, $0,-0.7268025403,-1.2559438371,-2.1717585494$
H,0,0.3209990933,-1.2531490096,-2.4666122724 H, $0,-1.2521495856,-2.1622330677,-2.4673775201$ C, $0,-1.4328748312,-0.0320038415,-2.3295184433$ C,0,-1.4492654519,2.5110949414,-2.5949887517 H, $0,-0.9096333055,3.3993327161,-2.2585070931$ $\mathrm{H}, 0,-1.4486269085,2.5554063104,-3.6903968963$ C, $0,-2.9030122696,2.5133485716,-0.3949081171$ H, $0,-3.9508139033,2.5105537429,-0.1000543947$ H, $0,-2.3776652251,3.4196378025,-0.0992891461$ C, $0,-3.6279002234,1.2536831598,-2.594609084$ $\mathrm{H}, 0,-4.6668034588,1.2299330133,-2.2572898612$ $\mathrm{H}, 0,-3.6682298292,1.2752872522,-3.6899753497$ C, $0,-2.8927001449,2.4953847874,-2.1096275931$ $\mathrm{H}, 0,-3.4256034815,3.4184751841,-2.3436972488$ $\mathrm{H}, 0,-0.2042113283,-2.1610704492,-0.2229694175$

Species 35

Charge $=0$ Multiplicity $=1$

C, $0,0.0094928021,0.0000284218,0.0066997953$ $\mathrm{H}, 0,0.0098255548,-0.0001173976,1.0988211108$ $\mathrm{H}, 0,1.0481713571,0.0000189894,-0.3307628488$ C, $0,-0.7215903045,1.2452584354,-0.5243615989$ C, $0,-0.7217210331,-1.2449885377,-0.5246882444$ C,0,-2.1695418206,-1.2625715992,-0.0203250431 $\mathrm{H}, 0,-2.1811440429,-1.2868351631,1.072903957$ $\mathrm{H}, 0,-2.6729783562,-2.1660585437,-0.3752529612$ C, $0,-2.1694109484,1.2628616237,-0.0199990098$ $\mathrm{H}, 0,-2.6727517963,2.1664913783,-0.374698929$ $\mathrm{H}, 0,-2.1810145665,1.286847985,1.0732359879$ C, $0,-2.8892494641,0.0002497923,-0.544876574$ $\mathrm{H}, 0,-3.9206479453,0.0002558388,-0.1796905591$ C, $0,-2.873495508,0.0004494465,-2.0850018593$ $\mathrm{H}, 0,-3.4005716811,-0.879905059,-2.4680823149$ $\mathrm{H}, 0,-3.4004831101,0.8809567722,-2.4678526291$ C, $0,-0.6900668078,1.26283832,-2.0566900818$ $\mathrm{H}, 0,0.3461483863,1.2853348141,-2.4055398036$ $\mathrm{H}, 0,-1.1822456928,2.1667475684,-2.4258074321$ C, $0,-0.6902045014,-1.262177576,-2.0570211579$ $\mathrm{H}, 0,0.3460056355,-1.2847035059,-2.4058825288$ H, $0,-1.1824907553,-2.1659351091,-2.4263674243$ C, $0,-1.4133770437,0.0004379677,-2.5778088585$ $\mathrm{H}, 0,-1.3857487989,0.0005808995,-3.6716161424$ Cl,0,0.1517916303,-2.7409312934,0.1102012207 $\mathrm{Cl}, 0,0.152071915,2.7409465553,0.1109186182$

Species 36

Charge $=0$ Multiplicity $=1$ C, $0,0.3136571698,-0.000002237,0.2286569813$ H, $0,0.321521768,-0.0001406112,1.3238876878$ 
H, $0,1.3590616474,-0.0000134335,-0.0977767508$ C, $0,-2.3336256066,-1.5384445726,0.1975679929$ $\mathrm{H}, 0,-2.3564596615,-1.5627455037,1.2928392852$ H, $0,-2.8489011168,-2.4416691228,-0.1478389224$ C, $0,-2.33346574,1.5387025961,0.1979803157$ $\mathrm{H}, 0,-2.8486582163,2.4420753618,-0.1471621614$ $\mathrm{H}, 0,-2.3562835488,1.5626942361,1.2932591197$ C,0,-3.1949910196,0.0005050428,-2.3181492156 $\mathrm{H}, 0,-3.7265748539,-0.8770641243,-2.7047684135$ $\mathrm{H}, 0,-3.7264627719,0.8782465813,-2.7045321145$ C, $0,-0.533534825,1.5387652939,-2.2808282498$ $\mathrm{H}, 0,0.500449658,1.5623999961,-2.6428472665$ $\mathrm{H}, 0,-1.021271828,2.4423529735,-2.6630882833$ C, $0,-0.5336542562,-1.538022485,-2.28122483$ $\mathrm{H}, 0,0.5003457687,-1.5615810011,-2.643207617$ $\mathrm{H}, 0,-1.0213979365,-2.4414882652,-2.6637611947$ $\mathrm{Cl}, 0,0.4424973385,-3.2554213515,0.320605938$ Cl,0,0.4428298938,3.2553779184,0.3214409448 Si, $0,-0.5541407379,-1.5480349608,-0.4038637213$ $\mathrm{Si}, 0,-0.553985483,1.5482789399,-0.4034625891$ Si,0,-3.259148569,0.000259178,-0.4255208187 $\mathrm{H}, 0,-4.6641065052,0.0002685193,0.0687565389$ Si, $0,-1.4147418746,0.0004934641,-2.9666419886$ $\mathrm{H}, 0,-1.3792765078,0.0006775542,-4.4555829187$

Species 37

Charge $=0$ Multiplicity $=1$ C, $0,0.3862133842,-0.0000072389,0.2814782182$ $\mathrm{H}, 0,0.3809357848,-0.0001472979,1.3777158346$ H, $0,1.4287662615,-0.0000112802,-0.0569446164$ C, $0,-2.3723333603,-1.293345292,0.1106681535$ $\mathrm{H}, 0,-2.4818048195,-1.2662304177,1.2018926868$ $\mathrm{H}, 0,-2.9355088908,-2.1679594311,-0.2396619245$ C, $0,-2.3722094956,1.2936242508,0.1110171803$ $\mathrm{H}, 0,-2.9353096027,2.1683848843,-0.2390679321$ $\mathrm{H}, 0,-2.4816717217,1.2662211721,1.2022356727$ C, $0,-2.8527210076,0.0004556101,-2.0700859771$ $\mathrm{H}, 0,-3.3866188315,-0.8776978798,-2.4574974599$ $\mathrm{H}, 0,-3.3865307493,0.8787671903,-2.4572603987$ C, $0,-0.6291395364,1.2935065069,-2.2909327635$ $\mathrm{H}, 0,0.3748117025,1.2648240601,-2.7323632579$ H, $0,-1.1347632809,2.1692283207,-2.7177170752$ C,0,-0.629252569,-1.2927413908,-2.2912700441 $\mathrm{H}, 0,0.3747039438,-1.2640226177,-2.7326865402$ H,0,-1.1349449222,-2.1683068961,-2.7182938796 $\mathrm{Cl}, 0,0.246362285,-3.3073617135,0.1770515087$ $\mathrm{Cl}, 0,0.2466774536,3.3073784066,0.1779256405$ Si, $0,-0.5691200749,1.4683021703,-0.4142324806$ Si, $0,-0.5692547715,-1.4680485926,-0.4146157414$ C, $0,-2.9726836162,0.0002528978,-0.5220859779$
H,0,-4.0477427564,0.0002740684,-0.2944659874 C,0,-1.4180889973,0.0004656151,-2.6660807806 $\mathrm{H}, 0,-1.5353275857,0.000613143,-3.7586167343$

Species 38

Charge $=0$ Multiplicity $=1$ C, $0,0.0775183824,0.0000158925,0.0558971289$ H,0,0.0824976328,-0.0001266179,1.1477358506 $\mathrm{H}, 0,1.1173562597,0.0000050978,-0.2772849888$ C, $0,-0.628512909,1.2925940005,-0.4564599984$ C, $0,-0.6286488028,-1.2923548865,-0.456797899$ C,0,-2.121460605,-1.2662287625,-0.072270503 H, $0,-2.2865923196,-1.1808279355,1.0024147422$ $\mathrm{H}, 0,-2.626044287,-2.1675973425,-0.427113895$ C, $0,-2.1213274155,1.2665264303,-0.0719399864$ $\mathrm{H}, 0,-2.6258155526,2.1680402831,-0.4265504559$ $\mathrm{H}, 0,-2.2864690923,1.1808623949,1.0027225307$ C, $0,-2.5054960695,0.0002673367,-0.8288036281$ C, $0,-3.0606675585,0.0004768136,-2.2227234124$ $\mathrm{H}, 0,-3.5410677378,-0.9090461339,-2.571832046$ H,0,-3.5409740062,0.9101389209,-2.5715981823 C, $0,-0.7254345294,1.2669727378,-1.9944932239$ $\mathrm{H}, 0,0.245232833,1.1823149737,-2.4847459782$ H, $0,-1.2198752032,2.1681406874,-2.3639438188$ C,0,-0.725568698,-1.266323934,-1.994824801 $\mathrm{H}, 0,0.2451069932,-1.1816398813,-2.4850567188$ $\mathrm{H}, 0,-1.2201053254,-2.1673435731,-2.3645088347$ C, $0,-1.5632199055,0.0003860863,-2.1263452488$ $\mathrm{Cl}, 0,0.2646928922,-2.7590737947,0.1924172993$ $\mathrm{Cl}, 0,0.2649816697,2.7590510957,0.1931362033$

Species 39

Charge $=0$ Multiplicity $=1$ C, $0,0.3111121489,0.0000040586,0.2291165935$ $\mathrm{H}, 0,0.3191139671,-0.0001466036,1.3246991736$ $\mathrm{H}, 0,1.360177755,0.0000013677,-0.0861768994$ C,0,-2.3309215561,-1.5579107548,0.1649084764 $\mathrm{H}, 0,-2.3932213005,-1.5694186939,1.2582093148$ $\mathrm{H}, 0,-2.8503792177,-2.4515912321,-0.1929565658$ C, $0,-2.3307856148,1.5581627128,0.1653287287$ $\mathrm{H}, 0,-2.8501662158,2.4519851918,-0.1922938011$ H,0,-2.3930851288,1.5693813347,1.2586326816 C,0,-3.3026028092,0.0005201794,-2.3909922339 $\mathrm{H}, 0,-3.8164019874,-0.884977214,-2.7649135939$ $\mathrm{H}, 0,-3.8163203455,0.8861702217,-2.7646644576$ C, $0,-0.563112698,1.5556394679,-2.2702682838$ H,0,0.4572801017,1.5600528765,-2.6680518554 H, $0,-1.0584106555,2.4521963994,-2.6538113857$ C, $0,-0.5632554769,-1.5548779071,-2.2706912248$ 
$\mathrm{H}, 0,0.4571353444,-1.5592774333,-2.66847977$

H, $0,-1.0586363645,-2.4512865319,-2.6544736474$ $\mathrm{Cl}, 0,0.5210545319,-3.2391865058,0.3742046556$ $\mathrm{Cl}, 0,0.5213343199,3.2391362903,0.3750892783$ Si,0,-3.2107334259,0.0002531777,-0.4941112939 Si, $0,-1.4703547002,0.0005077693,-2.8992460889$ Si, $0,-0.534327828,1.5619624647,-0.3906784344$ Si, $0,-0.5344651372,-1.5617134628,-0.3911044376$

Species 40

Charge $=0$ Multiplicity $=1$ C, $0,0.3984590515,-0.0000102827,0.290470756$ H, $0,0.4088290405,-0.0001568778,1.3851334432$ H, $0,1.4434049618,-0.0000129778,-0.0355222687$ C, $0,-2.3341572747,-1.2992372991,0.0189747737$ H, $0,-2.5855957396,-1.1624120918,1.0703429065$ H,0,-2.9464268812,-2.1143239272,-0.3737267199 C, $0,-2.3340373737,1.299533884,0.0193311494$ $\mathrm{H}, 0,-2.9462358523,2.1147835039,-0.3731427457$ $\mathrm{H}, 0,-2.5854822998,1.1624417266,1.0706630571$ C, $0,-3.0059945484,0.0004802133,-2.182482725$ $\mathrm{H}, 0,-3.4877141059,-0.908564493,-2.5320850167$ $\mathrm{H}, 0,-3.4876260889,0.9096678726,-2.5318340797$ C, $0,-0.7042752137,1.2992374565,-2.2253880053$ $\mathrm{H}, 0,0.2170576609,1.1613843553,-2.7906370905$ $\mathrm{H}, 0,-1.2673051384,2.1144800646,-2.6855393071$ C,0,-0.7043910291,-1.2984783362,-2.2257380739 $\mathrm{H}, 0,0.2169558636,-1.1605531202,-2.7909468161$ $\mathrm{H}, 0,-1.2674920742,-2.113546105,-2.6861116312$ $\mathrm{Cl}, 0,0.4118651117,-3.310563875,0.296567404$ $\mathrm{Cl}, 0,0.4121706954,3.3105372991,0.2974563273$ Si, $0,-0.4989109226,1.5330127143,-0.3626802707$ Si,0,-0.4990494069,-1.5327771206,-0.3630925349 C, $0,-2.4777937058,0.000263292,-0.7774761841$ C, $0,-1.506227027,0.0004012989,-2.1152614122$

Species 41

Charge $=0$ Multiplicity $=1$

C, $0,0.8842460776,-0.0004324396,0.7360282396$

$\mathrm{H}, 0,0.8868823753,-0.0049047613,1.8277282312$ H, $0,1.9233805298,0.0039399115,0.4013112383$ C,0,-1.2851526528,-1.3450727195,0.7122960345 $\mathrm{H}, 0,-1.2924770174,-1.3579632471,1.8049309462$ H, $0,-1.7473082944,-2.2651534547,0.3462390037$ C, $0,-1.2925639538,1.3316337032,0.723464445$ H, $0,-1.7605291533,2.2519918564,0.3655160082$ H,0,-1.2999337991,1.3349217832,1.8161886896 C, $0,-2.0594974948,0.0001095766,-1.4770074295$ $\mathrm{H}, 0,-2.4873782712,-0.8879271645,-1.9446587597$
H, $0,-2.4922536593,0.8896575749,-1.9372561792$ C,0,0.1264315789,1.2230899236,-1.3249598438 $\mathrm{H}, 0,1.1382970476,1.2103245191,-1.7366975526$ H,0,-0.3921012581,2.0993101121,-1.7190269979 C,0,0.1337612566,-1.2113960413,-1.3348467105 H, $0,1.1456296683,-1.1886588467,-1.7461941426$ H,0,-0.3789726991,-2.0875931416,-1.7364873876 B, $0,-1.8408827747,-0.0056382672,0.0753276013$ N,0,-0.5724993413,0.0054863107,-1.7596643578 C, $0,0.1655599899,1.2630046917,0.2140433605$ C, $0,0.1729174425,-1.2636236782,0.2036454319$ $\mathrm{Cl}, 0,1.1361133595,2.7446933212,0.7605224577$ $\mathrm{Cl}, 0,1.1517960716,-2.7442248553,0.7385033207$

Species 42

Charge $=0$ Multiplicity $=1$ C, $0,-0.000173422,-0.2846073746,-0.2317837915$ C, $0,0.0780744153,0.0499617458,1.8647184915$ C, $0,1.4328002912,-0.0064942134,2.5127958533$ H, $0,1.9119412292,-0.9768123365,2.5579870644$ $\mathrm{H}, 0,1.6003435137,0.6573360561,3.3520867087$ C, $0,1.3217489161,0.6312883802,1.1566039503$ C, $0,-0.401516565,1.8190927796,0.7903997375$ $\mathrm{O}, 0,-0.4008147344,-0.9223029987,0.9782410341$ $\mathrm{O}, 0,1.3983217855,-0.0813714888,-0.0460996525$ $\mathrm{O}, 0,-0.6543789988,0.9819197874,-0.3409610506$ $\mathrm{O}, 0,-0.7940028797,1.1391700198,1.9800522858$ O,0,1.0049639115,1.980230497,0.9555609269 $\mathrm{Cl}, 0,-1.227559794,3.3352621509,0.5836080282$ $\mathrm{Cl}, 0,-0.3545722879,-1.2415474726,-1.6398965916$

Species 43

Charge $=0$ Multiplicity $=1$

C,0,0.1427435025,0.0000497078,0.1046850054 $\mathrm{H}, 0,0.1237513792,-0.0073308158,1.1963414168$ $\mathrm{H}, 0,1.1782234031,0.0073508689,-0.2412637848$ $\mathrm{O}, 0,-2.4202239379,1.2921810919,-0.1045565078$ $\mathrm{O}, 0,-2.4075428018,-1.3158710239,-0.1225347099$ O, $0,-3.1580093972,0.0000677659,-2.3014709356$ O, $0,-0.8525932573,1.3150989901,-2.2569733865$ O, $0,-0.8393827389,-1.2913500976,-2.2744237785$ Si, $0,-0.8023623722,-1.523935776,-0.6026866117$ $\mathrm{Si}, 0,-0.8176936155,1.5237026546,-0.5818997403$ Si,0,-1.6232456467,0.0124802889,-2.9366502423 Si,0,-3.2915969342,-0.0125306224,-0.6458307161 $\mathrm{Cl}, 0,-5.2165489112,-0.0242444745,-0.0321791919$ $\mathrm{Cl}, 0,-1.6287657979,0.0243314805,-4.9571742075$ 
Species 44

Charge $=0$ Multiplicity $=1$

C,0,0.0830926864,-0.002763124,0.0597958466

H,0,0.0929722788,0.0177335644,1.1532132049

$\mathrm{H}, 0,1.1257177112,0.0181781589,-0.2698880007$

C, $0,-0.6276268138,1.2842633615,-0.4556298191$

C,0,-0.6035138691,-1.3173390097,-0.4385694558

C,0,-2.1083932867,-1.2677672708,-0.0738096247

$\mathrm{H}, 0,-2.3010070303,-1.1743287662,0.9975234064$

H,0,-2.6260010967,-2.1643560745,-0.4277964401

C, $0,-2.1212093708,1.2625721036,-0.0735895025$

$\mathrm{H}, 0,-2.6228031137,2.1676742104,-0.4248856284$

$\mathrm{H}, 0,-2.2892854906,1.1726167716,1.0004379528$

C, $0,-2.5001838657,-0.0024227776,-0.8382997485$

C,0,-3.0691609069,0.0023337868,-2.2292670975

$\mathrm{H}, 0,-3.5476718281,-0.9089457936,-2.5772430686$

$\mathrm{H}, 0,-3.5524650662,0.9102768873,-2.5803658071$

C, $0,-0.726888062,1.2631399213,-1.9935889247$

$\mathrm{H}, 0,0.2423720989,1.174366391,-2.4862806186$

H, $0,-1.2174043651,2.1677925667,-2.3613852773$

C,0,-0.7232352466,-1.2678858103,-1.9817776701

$\mathrm{H}, 0,0.2356817625,-1.1758927329,-2.4973782723$

$\mathrm{H}, 0,-1.2217232408,-2.1638471762,-2.3637446313$

C, $0,-1.5702534999,-0.002202479,-2.1182762503$

$\mathrm{Cl}, 0,0.2616810956,2.7635275992,0.1910461565$

H, $0,-0.064835831,-2.1880498145,-0.0472714446$

Species 45

Charge $=0$ Multiplicity $=1$

C,0,0.3229300814,-0.006570662,0.2377035797

$\mathrm{H}, 0,0.3331787932,0.0032593282,1.3340350144$

$\mathrm{H}, 0,1.3733568341,0.0039367755,-0.0756878077$

C,0,-2.3197901035,-1.5614078437,0.1649470614

$\mathrm{H}, 0,-2.3955523655,-1.5761345984,1.2588686786$

H,0,-2.8423338784,-2.4544826694,-0.1937461174

C, $0,-2.3260862039,1.5479617731,0.1673141857$

$\mathrm{H}, 0,-2.8432111824,2.4427730228,-0.1909859272$

$\mathrm{H}, 0,-2.3891832072,1.5596337818,1.2606728893$

C, $0,-3.3008162077,-0.0126682825,-2.3895141069$

$\mathrm{H}, 0,-3.8102411053,-0.9021104676,-2.7602522478$

$\mathrm{H}, 0,-3.8193640701,0.8685129701,-2.7665417053$

C,0,-0.5597091202,1.5452346886,-2.2661863276

$\mathrm{H}, 0,0.460598623,1.549671829,-2.6644882803$

$\mathrm{H}, 0,-1.0544842194,2.4429469872,-2.64758649$

C, $0,-0.5599134508,-1.5582839175,-2.2604665955$

$\mathrm{H}, 0,0.4569347317,-1.565683959,-2.6712046384$

$\mathrm{H}, 0,-1.0568548189,-2.4542691575,-2.6468133075$

$\mathrm{Cl}, 0,0.526595565,3.2266109048,0.3788532982$

Si, $0,-3.2107024951,-0.0111475919,-0.490689688$
Si, $0,-1.4672922397,-0.0107909722,-2.9003693564$ Si, $0,-0.5299463146,1.5443828116,-0.3872418597$ Si, $0,-0.5025580943,-1.5995472681,-0.3682793497$ H,0,0.249089852,-2.7793973694,0.1765191311

Species 46

Charge $=0$ Multiplicity $=1$

C, $0,0.4089191446,-0.0163454894,0.2982079959$ $\mathrm{H}, 0,0.4207903682,-0.0029388662,1.3935744768$ $\mathrm{H}, 0,1.4555193587,-0.0025734129,-0.0248461456$ C, $0,-2.3154608935,-1.3075665733,0.0147312439$ $\mathrm{H}, 0,-2.5885158443,-1.1655883547,1.0610771871$ $\mathrm{H}, 0,-2.9348080176,-2.1176291142,-0.3808212829$ C, $0,-2.3289249752,1.2912327716,0.0193880649$ H, $0,-2.935747448,2.1108334848,-0.3731249893$ $\mathrm{H}, 0,-2.588936606,1.1486619561,1.0678445523$ C, $0,-3.0137787164,-0.0050926803,-2.188018742$ H, $0,-3.4920240346,-0.9168735206,-2.535100015$ $\mathrm{H}, 0,-3.4975587556,0.9027813266,-2.5386527676$ C, $0,-0.7025831482,1.2910551357,-2.2208132835$ $\mathrm{H}, 0,0.2133377797,1.1478674445,-2.7933755957$ H,0,-1.2639592893,2.110780297,-2.6756161446 C,0,-0.7027567715,-1.3067293124,-2.2072834531 $\mathrm{H}, 0,0.2068057651,-1.1640216768,-2.7920394624$ $\mathrm{H}, 0,-1.2710371752,-2.1169171111,-2.6728756897$ $\mathrm{Cl}, 0,0.4248923904,3.2896649925,0.3068354844$ Si, $0,-0.4918354869,1.5110280335,-0.3576619729$ Si, $0,-0.4692741727,-1.5825909593,-0.3420229248$ C, $0,-2.4642724052,-0.0057441846,-0.7878286899$ C, $0,-1.5120315475,-0.0054485423,-2.0998170454$ $\mathrm{H}, 0,0.1778858793,-2.8454155282,0.1270992394$

\section{References}

1. Bader, R. F. W.; Chem. Rev. 1991, 91, 893; Bader, R. F. W.; Acc. Chem. Res. 1985, 18, 9; Popelier, P. In Atoms in Molecules, $1^{\text {st }}$ ed., Prentice Hall: Manchester, 2000.

2. Fradera, X.; Austen, M. A.; Bader, R. F. W.; J. Phys. Chem. A 1999, 103, 304; Merino, G.; Vela, A.; Heine, T.; Chem. Rev. 2005, 105, 3812.

3. Cyranski, M.; Krygowski, T. M.; Katritzky, A. R.; Schleyer, P.v.R.; J. Org. Chem. 2002, 67, 1333.

4. Cooper, D. L.; Gerratt, J.; Raimondi, M.; Nature 1986, 323, 699; Cooper, D. L.; Gerratt, J.; Raimondi, M.; Chem. Rev. 1991, 91, 929.

5. Pauling, L.; Wheland, G. W.; J. Phys. Chem. 1933, 1, 362.

6. Sironi, M.; Cooper, D. L.; Gerratt, J.; Raimondi, M.; J. Chem. Soc., Chem. Commun. 1989, 675; Cooper, D. L.; Wright, S. C.; Gerratt, J.; Raimondi, M.; J. Chem. Soc., Perkins Trans. 1989, $255,263$. 
7. In SCVB theory a bond is made by spin coupling two electrons and it allows the description of the different possible resonance structures. Havenith, R. W. A.; J. Org. Chem. 2006, 71, 3559;

8. Nascimento, M. A. C.; Barbosa, A. G. H.; Adv. Top. Theor. Chem. Phys. 2003, 247.

9. McWeeny, R.; Symmetry: An Introduction to Group Theory and its Applications, Dover: Mineola, 2002; Löwdin, P.O.; Rev. Mod. Phys. 1967, 39, 259.

10. Klein, D. J.; Carlisle, C. H.; Matsen, F. A.; Adv. Quantum Chem. 1970, 5, 219; Li, X.; Paldus, J.; J. Math. Chem. 1993, 13, 273; Altmann, S. L.; Herzig, P. In Point Group Theory Tables; Clarendon, 1994.

11. Nascimento, M. A. C.; Barbosa, A. G. H. In Fundamental World of Quantum Chemistry; Brändas, E. J.; Kryachko, E. S., eds.; Kluwer: Dordrech, 2003, Vol. 1.
12. Klein, D. J.; Carlisle, C. H.; Matsen, F. A.; Adv. Quantum Chem. 1970, 5, 219.

13. Li, X.; Paldus, J.; J. Math. Chem. 1993, 13, 273.

14. Altmann, S. L.; Herzig, P. In Point Group Theory Tables; Clarendon, 1994.

15. Cooper, D. L.; Gerratt, J.; Raimondi, M.; Nature 1986, 323, 699; Cooper, D. L.; Gerratt, J.; Raimondi, M.; Chem. Rev. 1991, 91, 929.

16. Popelier, P.; Atoms in Molecules, $1^{\text {st }}$ ed., Prentice Hall: Manchester, 2000, p. 132.

17. Bader, R. F. W.; Srebrenik, S.; Nguyen-Dang, T. T.; J. Chem. Phys. 1978, 68, 3680; Srebrenik, S.; Bader, R. F. W.; J. Chem. Phys. 1975, 63, 3945 .

18. Bader, R. F. W.; Beddall, P. M.; J. Am. Chem. Soc. 1973, 95, 305. 